\title{
Bioactive compounds recovery optimization from vine pruning residues using conventional heating and microwave-assisted extraction methods
}

\author{
Meirielly S. Jesus, Zlatina Genisheva, Aloia Romaní, Ricardo N. Pereira, José A. Teixeira*, \\ Lucília Domingues
}

CEB - Centre of Biological Engineering, University of Minho, Campus Gualtar, Braga, Portugal

\author{
A R T I C L E I N F O \\ Chemical compounds studied in this article: \\ ABTS(PubChem CID: 90658258) \\ Apigenin(PubChem CID: 5280443) \\ Catechin(PubChem CID: 73160) \\ Cinnamicacid (PubChem CID: 444539) \\ DPPH(PubChem CID: 2735032) \\ Ellagicacid (PubChem CID: 5281855) \\ Ferulicacid (PubChem CID: 445858) \\ Gallicacid (PubChem CID: 370) \\ Iron(II)sulfate (PubChem CID: 24393) \\ Iron(III)Cloride (PubChem CID: 24380) \\ Narigenin(PubChem CID: 932) \\ o-cumaricacid (PubChem CID: 637540) \\ p-cumaricacid + epicatechin (PubChem CID: \\ 637542) \\ Quercetin(PubChem CID: 5280343) \\ Resveratrol(PubChem CID: 445154) \\ Rutin(PubChem CID: 5280805) \\ Rosmarinicacid (PubChem CID: 5281792) \\ Syringicacid (PubChem CID: 10742) \\ Trolox(PubChem CID: 40634) \\ TPTZ(PubChem CID: 77258) \\ Vanillicacid (PubChem CID: 8468) \\ Keywords: \\ Vine pruning residue \\ Extraction \\ Polyphenols \\ Antioxidant
}

\section{Introduction}

High volumes of agricultural wastes and byproducts are produced from agro-food industry every year. In Mediterranean regions, the wine industry generates a significant amount of these residues (namely stems, peels, seeds, vine leaves, vine pruning or shoots) with no economic value, which are directly discarded causing environmentally problems (Delgado-Torre et al., 2012; Teixeira et al., 2014). Recycling and reusing these wastes to obtain added-value compounds is mandatory to promote the circular Economy, and thus achieve a sustainable growth of our society. In this context, these residues are recognized sources of polyphenolic compounds with interesting biological activities which help for the prevention of inflammatory processes, cardiovascular problems and prevention of oxidative reactions (Teixeira et al., 2014). Therefore, the research on the extraction of these natural bioactive compounds from winemaking byproducts has recently increased (Domínguez-Perles et al., 2014; Lachman et al., 2016; Piñeiro et al., 2017; Pintać et al., 2018).

\footnotetext{
* Corresponding author.

E-mail address: jateixeira@deb.uminho.pt (J.A. Teixeira).
} 


Nomenclature
$\begin{array}{ll}\text { Abbreviations } \\ \text { ABTS } & \text { 2,2'-azino-bis-3-ethylbenzthiazoline-6-sulphonic acid } \\ \text { CCD } & \text { Central composite design } \\ \text { CHE } & \text { Conventional heating extraction } \\ \text { DPPH } & \text { 2,2-diphenyl-1-picryl-hydrazyl-hydrate } \\ \text { FPU } & \text { Filter Paper Units } \\ \text { GAE } & \text { Gallic Acid Equivalent } \\ \text { FE (II) } & \text { ferrous equivalents } \\ \text { mha } & \text { Million Hectares } \\ \text { mhl } & \text { Million hectoliters } \\ M H z & \text { Megahertz } \\ M A E & \text { Microwave-assisted extraction } \\ \text { RSM } & \text { Response surface methodology } \\ U H P L C & \text { Ultra-high-performance liquid chromatography }\end{array}$

Among these residues, vine pruning residue is a lignocellulosic material composed by non-structural components (extractives, ashes, proteins) and structural components (cellulose, hemicellulose and lignin) which can be processed for the production of oligosaccharides and cellulosic ethanol (Jesus et al., 2017). In addition, extractives can be also considered as target fraction for an integral valorization of these lignocellulosic materials (Gullón et al., 2017). The content of the extractives in vine pruning residue can vary from 3.1 to $16.6 \% 16.6 \%$ (Dávila et al., 2016; Buratti et al., 2015; Jesus et al., 2017), which could depend on the cultivar, different growth regions (Delgado-Torre et al., 2012) and/or conditions of post-pruning and time of storage (Cebrián et al., 2017). In spite of representing a low percentage fraction, the recovery and separation from extractives of valuable products with high market price (such as terpenes, esters, stilbenes, flavonoids or other antioxidant phenols) could improve the economic profitability of the process (Cebrián et al., 2017).

Traditional methods used for the phenolic compounds extraction employ toxic solvents such as methanol-water mixtures (Delgado-Torre et al., 2012) and long times of heating, which results in high energy requirements and also in the degradation of thermal-labile molecules (Galanakis et al., 2013). The application of the extracted bioactive compounds for a human use makes mandatory the optimization of processes based on nontoxic solvents such as water or ethanol-water mixtures. Alternative techniques of extraction have been used for the recovery of phenolic compounds from vine pruning residues, including hydrothermal treatment at high temperatures (Jesus et al., 2017; Gullón et al., 2017), ultrasonic-assisted extraction (Jing et al., 2015; Kazibwe et al., 2017), alkaline hydrolysis treatments (Max et al., 2010), pulsed electric field extraction (Rajha et al., 2015) and microwave-assisted extraction (MAE) (Calinescu et al., 2017; Ranic et al., 2014; Spigno and De Faveri, 2009). Among these alternatives, the microwaveassisted treatment is considered an efficient method of extraction since, it requires low energy and short times of extraction (Delgado-Torre et al., 2012; Luque-Rodríguez et al., 2006; Piñeiro et al., 2017; Proestos and Komaitis, 2008). The electromagnetic dipole rotation between the molecules and the heating generated in the MAE solvent are responsible for the higher recovery of extracts with high content of the target compound. Polar molecules, such as water inside the plant cell, are heated instantaneously by microwave, where evaporation generates high pressure on the walls of cells due to the swelling of the plant cell, pushing and stretching the cell wall causing them to be destroyed. This process facilitates the release of the bioactive compounds from the cells, increasing the extraction yield. This efficiency can vary accordingly to the parameters adopted for the extraction such as time, temperature and solid-liquid ratio, concentration and type of solvent used (Mandal et al., 2007; Proestos and Komaitis, 2008).

\section{$V P R \quad$ Vine Pruning Residue}

Parameters and constants

\begin{tabular}{ll}
$A_{O}$ & Absorbance of control (DPPH or ABTS) \\
$A_{1}$ & Absorbance of extracts \\
$\beta_{0 i}, \beta 1 i, \beta 2 i, \beta 3 i, \beta 11 i, \beta 22, \beta 33 i, \beta 12 i, \beta 13 i$ and $\beta 23 i$ Are regression \\
\multicolumn{1}{c}{ coefficients calculated from experimental } \\
$I a$ & Inhibition activity (\%) \\
$I C_{50}$ & Concentration of sample or standard that can inhibit $50 \%$ \\
& of DPPH or ABTS (mg / mL) \\
$R^{2}$ & Coefficient determination \\
$x_{1}$ & Extraction time (min) \\
$x_{2}$ & Extraction Temperature $\left({ }^{\circ} \mathrm{C}\right)$ \\
$x_{3}$ & Concentration of ethanol (\%) \\
$y_{i}$ & Concentration total phenolics extracted, antioxidant ca- \\
& pacity or phenolic compounds (Apigenin and Ellagic acid)
\end{tabular}

Recently, vine pruning residue was subjected to two sequential stages of hydrothermal treatment to produce cellulosic ethanol and hemicellulosic liquors enriched in xylooligosaccharides and phenolic compounds with antioxidant activity (Jesus et al., 2017). On the basis of the previous work, a study of phenolic compounds extraction, as first stage for the biorefinery of vine pruning residue, is proposed. Thus, the aim of this work was the optimization of phenolic compound extraction by conventional heating and microwave assisted methods through an experimental design in which temperature, time and percentage of ethanol-water were evaluated. The antioxidant activity (based on FAP, DPPH and ABTS methods) were determined and phenolic compounds were identified and quantified.

\section{Materials and methods}

\subsection{Raw material and analysis of chemical composition}

Vine pruning residue (VPR) from V. vinifera variety Loureiro were collected and gently given away by a producer from the Minho region (North of Portugal), in January of 2015. The material was dried at room temperature, milled (Retsch SM100) in to pass an $8 \mathrm{~mm}$ mesh and homogenized in a single batch. The moisture content was determined using a Moisture Analyser (Radwag MAC 50/1/NH) and was $17.6 \pm 0.12$ and stored at room temperature in a dark and dry place until its use. The chemical composition of the VPR was previously analyzed by Jesus et al. (2017). VPR composition was as follows (expressed in $\mathrm{g}$ per $100 \mathrm{~g}$ VPR on oven-dry basis \pm standard deviation based in three replicate determinations): $32.9 \pm 0.66$ of cellulose (as glucan); $14.87 \pm 0.17$ of xylan; $0.40 \pm 0.06$ of arabinan; $3.95 \pm 0.52$ of acetyl groups; $29.5 \pm 1.21$ of Klason lignin; $13.7 \pm 1.02$ of extractives in water; $2.94 \pm 0.89$ of extractives in ethanol and $3.32 \pm 0.56$ of ashes.

\subsection{Extraction of antioxidant compounds}

\subsubsection{Conventional heating extraction (CHE)}

Conventional heating extraction (CHE) treatment was carried out in silicone oil bath with circulating heater and temperature control using $160 \mathrm{~mL}$ cylindrical reactors fabricated from 316 stainless steel. Previous study was performed to evaluate the range of variables to be evaluated (Table 1). For CHE assays, $0.5 \mathrm{~g}$ of VPR was mixed with $20 \mathrm{~mL}$ of ethanol-water (according to Moreira et al., 2018) ranging from 30 to $60 \%$, varying the temperature between room temperature $\left(25^{\circ} \mathrm{C}\right)$ and $100^{\circ} \mathrm{C}$ and time between 60 and $180 \mathrm{~min}$. Then, the extracted solution was recovered by filtration and the VPR extracts were stored at $4{ }^{\circ} \mathrm{C}$ until further use. 
Table 1

Experimental runs of the preliminary analyzes using different time (min) temperature $\left({ }^{\circ} \mathrm{C}\right)$ and ethanol $(\%)$ and total polyphenolic compound responses obtained.

\begin{tabular}{lllll}
\hline $\begin{array}{l}\text { Runs } \\
\text { v) }\end{array}$ & $\begin{array}{l}\text { Ethanol (\%v/ } \\
\text { vemperature }\left({ }^{\circ} \mathrm{C}\right)\end{array}$ & $\begin{array}{l}\text { Time } \\
(\mathrm{min})\end{array}$ & $\begin{array}{l}\text { TPC }(\mathrm{g} \text { GAE } / 100 \mathrm{~g} \\
\text { VPR })\end{array}$ \\
\hline 1 & 60 & 80 & 120 & $1.9 \pm 0.05^{\mathrm{cd}}$ \\
2 & 30 & 80 & 120 & $2.0 \pm 0.09^{\mathrm{cd}}$ \\
3 & 45 & 80 & 60 & $1.7 \pm 0.01^{\mathrm{bc}}$ \\
4 & 45 & 80 & 180 & $2.1 \pm 0.03^{\mathrm{d}}$ \\
5 & 45 & 60 & 120 & $1.5 \pm 0.01^{\mathrm{a}}$ \\
6 & 45 & 100 & 120 & $2.0 \pm 0.01^{\mathrm{cd}}$ \\
7 & 45 & 25 & 120 & $1.2 \pm 0.02^{\mathrm{a}}$ \\
\hline
\end{tabular}

* The averages followed by the same letters do not differ by the Tukey test $(p<0.05)$. TPC: total phenolic compounds; GAE: gallic acid equivalents.

After evaluation of preliminary results, an experimental design $\left(2^{3}\right)$ was carried out for the optimization of phenolic compounds extraction, where the variables extraction time (19-221 $\mathrm{min}$ ), ethanol concentration $(20-70 \% \mathrm{v} / \mathrm{v})$ and extraction temperature $\left(46-114^{\circ} \mathrm{C}\right)$ were evaluated. A liquid to solid ratio of $40: 1 \mathrm{~mL} / \mathrm{g}$ of VPR was selected for CHE experiments. Table 2 shows the conditions of experiments carried out. After conventional extraction, VPR extracts were recovered by filtration, as described above. All the experiments were conducted in triplicate.

The independent variables: extraction time $\left(x_{1}, \mathrm{~min}\right)$, extraction temperature $\left(x_{2},{ }^{\circ} \mathrm{C}\right)$, and concentration of ethanol $\left(x_{3}, \%\right)$ were correlated with the dependent variables (phenolic compounds and antioxidant activity) by the follow equation:

$$
\begin{aligned}
y_{i}= & \beta_{0 i}+\beta_{1 i} x_{1}+\beta_{2 i} x_{2}+\beta_{3 i} x_{3}+\beta_{11 i} x_{1}^{2}+\beta_{22 i} x_{2}^{2} \\
& +\beta_{33 i} x_{3}^{2}+\beta_{12 i} x_{1} x_{2}+\beta_{13 i} x_{1} x_{3}+\beta_{23 i} x_{2} x_{3}
\end{aligned}
$$

Where, $y_{i}(i=1$ to 6$)$ are the dependent variables corresponding to concentration of total phenolics extracted, antioxidant activity (g GAE/ $100 \mathrm{~g}$ VPR, $g$ FE (II) $/ 100 \mathrm{~g}$ VPR and $\mathrm{g}$ TE/ $100 \mathrm{~g}$ VPR) or phenolic compounds (apigenin mg/100 $\mathrm{g}$ VPR and ellagic acid mg/100 $\mathrm{g}$ VPR); $x_{1}, x_{2}$ and $x_{3}$ value of independent variables; $\beta_{0 i} \beta_{1 i} \beta_{2 i} \beta_{3 i} \beta_{11 i} \beta_{22 i}$ $\beta_{33 i} \beta_{12 i} \quad \beta_{13 i}$ and $\beta_{23 i}$ are regression coefficients calculated from experimental data by multiple regression using the least-squares method. The experimental data were fitted to the proposed model using commercial software (Statistica). The goodness of model fitting was evaluated by the coefficient determination $R^{2}$ and the statistical significance by the Fisher's F-test for analysis of variable with a $95 \%$ confidence level. Significant differences among the results were evaluated by the one-way analysis of variance (ANOVA) followed by the Tukey's HSD.

\subsubsection{Microwave-assisted extraction (MAE)}

Alternative microwave-assisted extraction of phenolic compounds from VPR, were carried out in a Speedwave 4 microwave digester. Conditions of microwave extraction were selected based on conventional heating extraction treatment. For the extraction of phenolic compounds, the liquid to solid ratio was $40 \mathrm{~mL}$ of ethanol-water per $1 \mathrm{~g}$ of VPR. The percentage of ethanol-water varied from 0 to $60 \%(\mathrm{v} / \mathrm{v})$. Microwave extraction assays were carried out at temperature ranging from 60 to $120^{\circ} \mathrm{C}$ for 5 or $40 \mathrm{~min}$ (Table 3). Extracts were recovered by filtration. The experiments were conducted in triplicate.

\subsection{Total phenolic compounds (TPC) analysis}

Total phenol compounds in VPR extracts were analyzed based on the spectrophotometric method described by Meneses et al. (2013). Briefly, $5 \mu \mathrm{L}$ of the extract, $60 \mu \mathrm{L}$ of $7.5 \%(\mathrm{w} / \mathrm{v})$ aqueous sodium carbonate solution, $15 \mu \mathrm{L}$ of Folin-Ciocalteu reconstitution agent and $200 \mu \mathrm{L}$ of distilled water were mixed in 96-well microplate. The mixture was incubated for $6 \mathrm{~min}$ at $60^{\circ} \mathrm{C}$ and the absorbance was measured at $700 \mathrm{~nm}$ against a blank sample using a Microplate reader for UV-vis absorbance (Synergy HT-BIOTEK). A calibration curve was prepared using standard solution of gallic acid $(125,250,500,750,1000,2000$, and $3000 \mathrm{mg} / \mathrm{L})$. The results were expressed as $\mathrm{g}$ of gallic acid equivalents per $100 \mathrm{~g}$ dry material ( $\mathrm{g} \mathrm{GAE} / 100 \mathrm{~g}$ VPR).

Table 2

Experimental runs using coded levels of time (min. $\left.x_{1}\right)$, temperature $\left({ }^{\circ} \mathrm{C} x_{2}\right)$ and ethanol $\left(\% x_{3}\right)$ according to the $2^{3}$ full factorial central composite design and

\begin{tabular}{|c|c|c|c|c|c|c|c|c|c|}
\hline \multicolumn{4}{|c|}{ Independent variables } & \multirow[t]{2}{*}{ Symbol } & \multicolumn{4}{|l|}{ Range and levels } & \multirow[b]{2}{*}{1.68} \\
\hline & & & & & -1.68 & -1 & 0 & 1 & \\
\hline \multicolumn{4}{|c|}{ Extraction time (min) } & $\mathrm{x} 1$ & 19 & 60 & 120 & 180 & 221 \\
\hline \multicolumn{4}{|c|}{ Extraction Temperature $\left({ }^{\circ} \mathrm{C}\right)$} & $\mathrm{x} 2$ & 46 & 60 & 80 & 100 & 114 \\
\hline \multicolumn{4}{|c|}{ Concentration of ethanol (\%) } & $\mathrm{x} 3$ & 20 & 30 & 45 & 60 & 70 \\
\hline \multirow[t]{2}{*}{ Runs } & Coded va & ables lev & & & & & & & \\
\hline & $x_{1}(\min )$ & $x_{2}\left({ }^{\circ} \mathrm{C}\right)$ & $x_{3}(\% \mathrm{v} / \mathrm{v})$ & TPC (g GAE/100 g VPR) & FRAP (g FE/100 g VPR) & DPPH ( $g$ TE/100 g VPR) & $\mathrm{IC}_{50}(\mathrm{~g} / \mathrm{L})$ & ABTS (g TE/100 g VPR) & $\mathrm{IC}_{50}(\mathrm{~g} / \mathrm{L})$ \\
\hline 1 & 60 & 60 & 30 & $1.5 \pm 0.04^{\mathrm{ab}}$ & $1.8 \pm 0.06^{\mathrm{a}}$ & $3.4 \pm 0.22^{\mathrm{abc}}$ & $12.3 \pm 0.02$ & $1.0 \pm 0.01^{\mathrm{a}}$ & $8.1 \pm 0.41$ \\
\hline 2 & 60 & 60 & 60 & $1.6 \pm 0.06^{\mathrm{bcd}}$ & $1.7 \pm 0.03^{\mathrm{a}}$ & $3.1 \pm 0.08^{\mathrm{ab}}$ & $12.8 \pm 0.05$ & $1.3 \pm 0.02^{\mathrm{b}}$ & $6.7 \pm 0.15$ \\
\hline 3 & 180 & 60 & 30 & $1.2 \pm 0.013^{\mathrm{a}}$ & $1.9 \pm 0.05^{\mathrm{a}}$ & $4.2 \pm 0.14^{\text {cde }}$ & $6.2 \pm 0.11$ & $1.8 \pm 0.02^{\mathrm{c}}$ & $3.7 \pm 0.10$ \\
\hline 4 & 180 & 60 & 60 & $1.5 \pm 0.05^{\mathrm{abc}}$ & $3.0 \pm 0.16^{\mathrm{c}}$ & $3.9 \pm 0.12^{1 \mathrm{abcd}}$ & $7.6 \pm 0.26$ & $2.0 \pm 0.02^{\mathrm{cd}}$ & $3.3 \pm 0.04$ \\
\hline 5 & 60 & 100 & 30 & $1.5 \pm 0.03^{\mathrm{abc}}$ & $2.3 \pm 0.08^{\mathrm{ab}}$ & $4.0 \pm 0.12^{\mathrm{bcd}}$ & $12.8 \pm 0.22$ & $2.1 \pm 0.02^{\text {def }}$ & $5.2 \pm 0.06$ \\
\hline 6 & 60 & 100 & 60 & $1.8 \pm 0.06^{\mathrm{def}}$ & $1.9 \pm 0.05^{\mathrm{a}}$ & $2.9 \pm 0.18^{\mathrm{ab}}$ & $12.6 \pm 0.01$ & $2.2 \pm 0.05^{\mathrm{fghi}}$ & $2.9 \pm 0.11$ \\
\hline 7 & 180 & 100 & 30 & $1.7 \pm 0.08^{\mathrm{cdf}}$ & $2.9 \pm 0.07^{\mathrm{bc}}$ & $3.8 \pm 0.14^{\mathrm{abcd}}$ & $7.7 \pm 0.07$ & $2.3 \pm 0.03^{\text {fghi }}$ & $2.9 \pm 0.14$ \\
\hline 8 & 180 & 100 & 60 & $2.1 \pm 0.05^{\mathrm{fg}}$ & $3.0 \pm 0.04^{\mathrm{c}}$ & $4.4 \pm 0.12^{\mathrm{bcd}}$ & $6.6 \pm 0.02$ & $2.4 \pm 0.01^{\mathrm{hi}}$ & $2.6 \pm 0.03$ \\
\hline 9 & 19 & 80 & 45 & $2.0 \pm 0.15^{\text {efg }}$ & $2.0 \pm 0.13^{\mathrm{ab}}$ & $3.7 \pm 0.07^{\mathrm{abcd}}$ & $8.4 \pm 0.05$ & $2.2 \pm 0.01^{\text {efgh }}$ & $3.0 \pm 0.09$ \\
\hline 10 & 221 & 80 & 45 & $2.2 \pm 0.05^{g}$ & $1.9 \pm 0.05^{\mathrm{a}}$ & $5.3 \pm 0.02^{\mathrm{ef}}$ & $5.6 \pm 0.08$ & $2.5 \pm 0.06^{\mathrm{a}}$ & $2.5 \pm 0.15$ \\
\hline 11 & 120 & 46 & 45 & $1.5 \pm 0.03^{\mathrm{bcd}}$ & $2.3 \pm 0.07^{\mathrm{ab}}$ & $3.1 \pm 0.03^{\mathrm{ab}}$ & $13.0 \pm 0.01$ & $2.4 \pm 0.06^{\mathrm{ghi}}$ & $3.2 \pm 0.05$ \\
\hline 12 & 120 & 114 & 45 & $2.2 \pm 0.02^{g}$ & $2.3 \pm 0.17^{\mathrm{a}}$ & $5.7 \pm 0.04^{f}$ & $4.9 \pm 0.12$ & $2.3 \pm 0.01^{\text {efgh }}$ & $2.3 \pm 0.09$ \\
\hline 13 & 120 & 80 & 20 & $1.3 \pm 0.03^{\mathrm{ab}}$ & $2.2 \pm 0.2^{\mathrm{a}}$ & $2.8 \pm 0.08^{\mathrm{a}}$ & $7.3 \pm 0.15$ & $2.0 \pm 0.02^{\mathrm{de}}$ & $3.1 \pm 0.02$ \\
\hline 14 & 120 & 80 & 70 & $1.5 \pm 0.16^{2 \mathrm{bcd}}$ & $2.1 \pm 0.13^{\mathrm{a}}$ & $4.5 \pm 0.06^{\mathrm{de}}$ & $6.9 \pm 0.31$ & $2.0 \pm 0.02^{\mathrm{cd}}$ & $2.2 \pm 0.01$ \\
\hline 15 & 120 & 80 & 45 & $2.2 \pm 0.08^{g}$ & $4.2 \pm 0.04^{d}$ & $4.7 \pm 0.18^{\text {def }}$ & $6.5 \pm 0.10$ & $2.2 \pm 0.09^{\text {efgh }}$ & $2.3 \pm 0.21$ \\
\hline 16 & 120 & 80 & 45 & $2.2 \pm 0.06^{g}$ & $4.3 \pm 0.18^{\mathrm{d}}$ & $4.3 \pm 0.11^{\text {cde }}$ & $6.5 \pm 0.08$ & $2.2 \pm 0.01^{\text {efgh }}$ & $2.1 \pm 0.19$ \\
\hline 17 & 120 & 80 & 45 & $2.1 \pm 0.06^{g}$ & $4.5 \pm 0.17^{\mathrm{d}}$ & $4.7 \pm 0.18^{\text {cde }}$ & $6.6 \pm 0.04$ & $2.3 \pm 0.01^{\mathrm{fgh}}$ & $2.3 \pm 0.14$ \\
\hline 18 & 120 & 80 & 45 & $2.2 \pm 0.03^{g}$ & $4.7 \pm 0.03^{\mathrm{d}}$ & $4.7 \pm 0.23^{\text {cde }}$ & $6.2 \pm 0.17$ & $2.3 \pm 0.02^{\mathrm{fgh}}$ & $2.7 \pm 0.02$ \\
\hline
\end{tabular}
extraction of polyphenolic compounds and antioxidant activity obtained under those conditions.

" The averages followed by the same letters do not differ by the Tukey test $(p<0.05)$. TPC: total phenolic compounds; GAE: gallic acid equivalents; FE ferrous equivalents; TE: trolox equivalents. Antiradical activity is expressed as a mean $(\mathrm{n}=3)$ of $\mathrm{IC}_{50}$ values ( $\mathrm{g}$ of extract/L of solution). 
Table 3

Total phenolic content and antioxidant activity from extracts obtained by microwave-assisted extraction.

\begin{tabular}{|c|c|c|c|c|c|c|c|c|c|c|}
\hline Runs & $\begin{array}{l}\text { Ethanol } \\
\text { concentration (\% v/ } \\
\text { v) }\end{array}$ & Temperature $\left({ }^{\circ} \mathrm{C}\right)$ & $\begin{array}{l}\text { Time } \\
\text { (min) }\end{array}$ & $\begin{array}{l}\text { TPC }(g \text { GAE } / 100 \mathrm{~g} \\
\text { VPR) }\end{array}$ & $\begin{array}{l}\text { FRAP (g FE (II)/ } \\
100 \mathrm{~g} \text { VPR) }\end{array}$ & DPPH (g TE/100 g & VPR) & $\mathrm{IC}_{50}(\mathrm{~g} / \mathrm{L})$ & $\begin{array}{l}\text { ABTS }(g \text { TE} / 100 g \\
\text { VPR) }\end{array}$ & $\mathrm{IC}_{50}(\mathrm{~g} / \mathrm{L})$ \\
\hline 1 & 60 & 120 & 40 & $2.3 \pm 0.10^{\mathrm{c}}$ & $9.5 \pm 0.45^{\mathrm{e}}$ & $3.2 \pm 0.02^{\mathrm{ab}}$ & $4.9 \pm$ & 0.40 & $3.3 \pm 0.03^{\mathrm{b}}$ & $1.3 \pm 0.17$ \\
\hline 2 & 60 & 120 & 25 & $2.2 \pm 0.10^{\mathrm{bc}}$ & $8.5 \pm 0.02^{\mathrm{ef}}$ & $3.2 \pm 0.02^{\mathrm{ab}}$ & $5.4 \pm$ & 0.43 & $3.2 \pm 0.10^{\mathrm{ab}}$ & $1.4 \pm 0.27$ \\
\hline 3 & 60 & 120 & 10 & $2.3 \pm 0.02^{\mathrm{c}}$ & $6.5 \pm 0.03^{a b}$ & $3.1 \pm 0.05^{\mathrm{ab}}$ & $5.3 \pm$ & 0.21 & $3.3 \pm 0.04^{\mathrm{b}}$ & $2.4 \pm 0.25$ \\
\hline 4 & 60 & 120 & 5 & $2.4 \pm 0.01^{\mathrm{c}}$ & $7.5 \pm 0.07^{\mathrm{bcd}}$ & $4.3 \pm 0.06^{\mathrm{c}}$ & $6.4 \pm$ & 0.12 & $3.4 \pm 0.20^{\mathrm{b}}$ & $3.0 \pm 0.38$ \\
\hline 5 & 60 & 90 & 10 & $2.15 \pm 0.02^{\mathrm{bc}}$ & $7.2 \pm 0.01^{\mathrm{abc}}$ & $2.3 \pm 0.06^{\mathrm{a}}$ & $6.5 \pm$ & 0.50 & $3.0 \pm 0.10^{\mathrm{ab}}$ & $2.0 \pm 0.04$ \\
\hline 6 & 60 & 90 & 5 & $2.1 \pm 0.02^{\mathrm{bc}}$ & $6.2 \pm 0.03^{\mathrm{ab}}$ & $3.8 \pm 0.01^{\mathrm{bc}}$ & $6.8 \pm$ & 0.64 & $2.7 \pm 0.04^{\mathrm{ab}}$ & $4.0 \pm 0.26$ \\
\hline 7 & 60 & 60 & 10 & $1.6 \pm 0.02^{\mathrm{a}}$ & $6.3 \pm 0.03^{a b}$ & $3.2 \pm 0.01^{a b}$ & - & & $2.9 \pm 0.04^{\mathrm{ab}}$ & - \\
\hline 8 & 60 & 60 & 5 & $1.8 \pm 0.05^{\mathrm{ab}}$ & $5.8 \pm 0.09^{\mathrm{a}}$ & $3.2 \pm 0.02^{\mathrm{ab}}$ & - & & $2.8 \pm 0.02^{\mathrm{ab}}$ & - \\
\hline 9 & 30 & 120 & 10 & $2.3 \pm 0.01^{\mathrm{c}}$ & $8.4 \pm 0.03^{\text {cde }}$ & $4.0 \pm 0.10^{\mathrm{bc}}$ & $5.5 \pm$ & 0.13 & $2.7 \pm 0.03^{\mathrm{ab}}$ & $2.2 \pm 0.19$ \\
\hline 10 & 30 & 120 & 5 & $2.4 \pm 0.01^{\mathrm{c}}$ & $7.5 \pm 0.10^{\mathrm{bcd}}$ & $4.0 \pm 0.01^{b c}$ & $3.6 \pm$ & 0.14 & $3.3 \pm 0.10^{\mathrm{b}}$ & $1.1 \pm 0.13$ \\
\hline 11 & 30 & 90 & 10 & $2.3 \pm 0.02^{\mathrm{c}}$ & $6.8 \pm 0.03^{a b c}$ & $3.9 \pm 0.01^{b c}$ & $3.7 \pm$ & 0.39 & $2.8 \pm 0.03^{\mathrm{ab}}$ & $2.6 \pm 0.67$ \\
\hline 12 & 30 & 90 & 5 & $2.3 \pm 0.02^{\mathrm{c}}$ & $4.1 \pm 0.02^{\mathrm{ab}}$ & $4.0 \pm 0.04^{\mathrm{c}}$ & $6.7 \pm$ & 0.07 & $2.8 \pm 0.07^{a b}$ & $2.4 \pm 0.05$ \\
\hline 13 & 30 & 60 & 10 & $1.6 \pm 0.01^{\mathrm{a}}$ & $6.2 \pm 0.09^{a b}$ & $3.3 \pm 0.03^{b c}$ & - & & $2.5 \pm 0.04^{\mathrm{ab}}$ & - \\
\hline 14 & 30 & 60 & 5 & $1.8 \pm 0.03^{\mathrm{ab}}$ & $5.9 \pm 0.06^{\mathrm{ab}}$ & $3.4 \pm 0.06^{\mathrm{ab}}$ & - & & $2.2 \pm 0.02^{\mathrm{c}}$ & - \\
\hline 15 & 0 & 120 & 10 & $1.5 \pm 0.01^{\mathrm{a}}$ & $5.6 \pm 0.06^{\mathrm{a}}$ & $3.5 \pm 0.02^{\mathrm{bc}}$ & - & & $2.7 \pm 0.01^{\mathrm{ab}}$ & - \\
\hline 16 & 0 & 120 & 40 & $2.4 \pm 0.01^{\mathrm{c}}$ & $6.3 \pm 0.05^{c}$ & $3.7 \pm 0.20^{a b}$ & $6.9 \pm$ & 0.67 & $3.0 \pm 0.03^{a b}$ & $2.6 \pm 0.25$ \\
\hline
\end{tabular}

*The averages followed by the same letters do not differ by the Tukey test $(p<0.05)$. TPC: total phenolic compounds; GAE: gallic acid equivalents; FE (II) ferrous equivalents; TE: trolox equivalents. Antiradical activity is expressed as a mean $(n=3)$ of $\mathrm{IC}_{50}$ values $(\mathrm{g}$ of extract/L of solution).

\subsubsection{UHPLC analysis}

Phenolic compounds present in the VPR extracts from conventional heating and microwave treatments were analyzed and quantified by Shimatzu Nexpera X2 UHPLC chromatograph equipped with Diode Array Detector (Shimadzu, SPD-M20 A). Separation was performed on a reversed-phase Aquity UPLC BEH C18 column $(2.1 \mathrm{~mm} \times 100 \mathrm{~mm}$, $1.7 \mu \mathrm{m}$ particle size; from Waters) and a precolumn of the same material at $40{ }^{\circ} \mathrm{C}$. The flow rate was $0.4 \mathrm{~mL} / \mathrm{min}$. The HPLC grade solvents used were water/formic acid $(0.1 \%)$ as solvent $\mathrm{A}$ and acetonitrile as solvent B. The elution gradient for solvent B was as follows: from 0.0 to $5.5 \mathrm{~min}$ eluent $\mathrm{B}$ at $5 \%$, from 5.5 to $17 \mathrm{~min}$ a linear increase to $60 \%$, from 17.0 to $18.5 \mathrm{~min}$ a linear increase to $100 \%$, then column equilibration from 18.5 to $30.0 \mathrm{~min}$ at $5 \%$. Phenolic compounds were identified by comparing their UV/Vis spectra and retention times with that of corresponding standards. Compounds were quantified and identified at different wave-lengths: ellagic acid at $250 \mathrm{~nm}$; vanillic acid at $254 \mathrm{~nm}$; catechin, narigenin, $p$-cumaric acid, epicatechin, gallic acid, syringic acid, o-cumaric acid and cinnamic acid at $280 \mathrm{~nm}$, trans-resveratrol at $308 \mathrm{~nm}$; apigenin and rosmarinic acid at $329 \mathrm{~nm}$; rutin at $350 \mathrm{~nm}$ and quercetin at $370 \mathrm{~nm}$. All calibration curves had $R^{2}$ between 0,997 and 0,999 . Concentration of the individual compounds in the calibration curves were between $250 \mathrm{mg} / \mathrm{L}$ and $1.25 \mathrm{mg} / \mathrm{L}$.

\subsection{Determination of antioxidant capacity}

\subsubsection{Ferric reducing antioxidant power (FRAP)}

The antioxidant activity by the ferric reducing antioxidant power (FRAP) was made according to the methodology previously described (Ballesteros et al., 2015; Meneses et al., 2013). FRAP reagent was freshly prepared by mixing a $10 \mathrm{mM}$ 2,4,6-tris (1-pyridyl)-5-triazine (TPTZ) solution in $40 \mathrm{mM} \mathrm{HCl}$ with a $20 \mathrm{mM}, \mathrm{FeCl}_{3}$ solution and $0.3 \mathrm{M}$ acetate buffer $(\mathrm{pH} 3.6)$ in a proportion 1:1:10 (v/v/v). A calibration curve was prepared with aqueous solution of $\mathrm{FeSO}_{4}(10,30,50,60,70$, $80,110,140,200$, and $275 \mathrm{mg} / \mathrm{L}$ ). In a 96-well microplate was added $10 \mu \mathrm{L}$ of the filtered and duly diluted extract with $290 \mu \mathrm{L}$ of FRAP reagent. Then, the reaction mixture was incubated at $37^{\circ} \mathrm{C}$ for $15 \mathrm{~min}$. After that, the absorbance was determined at $593 \mathrm{~nm}$ against a blank prepared with distilled water. FRAP values were expressed as grams of ferrous equivalent per $100 \mathrm{~g}$ of VPR extract ( $\mathrm{g} \mathrm{FE} / 100 \mathrm{~g}$ VPR).

\subsubsection{DPPH radical scavenging activity}

The activity DPPH was determined by measuring free radical scavenging the 2,2-diphenyl-1-picryl-hydrazyl-hydrate (Meneses et al.,
2013; Sánchez-Gómez et al., 2017a). The method consists in the reduction of the DPPH radical in the presence of hydrogen-donating antioxidant and in the formation of the non-radical DPPH-H form at the end of the reaction. The percentage of remaining DPPH was inversely proportional to the antioxidant concentration. The reaction was carried out in a 96-well microplate, samples $(10 \mu \mathrm{L})$ with extract were mixed with $290 \mu \mathrm{L}$ of DPPH in methanol $\left(6 \times 10^{-5} \mathrm{M}\right.$ dissolved in methanol absolute to an absorbance value of 0.700 at $515 \mathrm{~nm}$ ), incubated for $1 \mathrm{~h}$ at room temperature and the absorbance was measured at $515 \mathrm{~nm}$. The negative and positive controls were made with methanol and the Trolox standard, respectively. The inhibition activity (\%) of the DPPH radicals was calculated using the following equation:

$\%$ inhibition activity $=\frac{A_{0}-A_{1}}{A_{1}} \times 100$

Where $A_{0}$ was an absorption of the negative control and $A_{1}$ for an absorbance of the extracts. The sample concentration for the $50 \%$ reduction of DPPH radicals ( $\mathrm{IC}_{50}$ ) was calculated by interpolation. The $\mathrm{IC}_{50}$ values were expressed as $\mathrm{g}$ of Trolox equivalent per $100 \mathrm{~g}$ of dry weight material (g TE/100 $g$ VPR).

\subsubsection{Radical ABTS elimination capability}

The ABTS (2,2-azino-bis-3-ethylbenzthiazoline-6-sulphonic acid) cation decolorization assay was according to the methodology described by Ahmad Mir et al. (2017) adapted for 96-well microplates to evaluate the ability of the sample to eliminate free ABTS + radicals. ABTS $(7.4 \mathrm{mM})$ diluted in ethanol and potassium persulfate $(2.6 \mathrm{mM})$ were mixed in $1: 1(\mathrm{v} / \mathrm{v})$ ratio and incubated for $16 \mathrm{~h}$ at room temperature in the dark. To a $200 \mu \mathrm{L}$ of ABTS radical solution were added $10 \mu \mathrm{L}$ sample solution or ethanol and the mixture was allowed to stand for $1 \mathrm{~h}$ at $30^{\circ} \mathrm{C}$ to obtain a stable absorbance. Absorbance was measured at $734 \mathrm{~nm}$ against a blank. The results were expressed as percent inhibition using the Eq. 2 as described in the item 3.4.2.

\subsection{Statistical analysis}

All experiments were performed in triplicate and the results were expressed as mean value \pm standard deviation. The statistical analysis of model was carried out using StatSoft Statistica software (version 10). 


\section{Results and discussion}

\subsection{Conventional heating extraction ( $\mathrm{CHE})$}

\subsubsection{Effect of temperature, time and ethanol percentage on phenolic} compounds extraction: preliminary experiments

The temperature, solvent concentration and time of extraction are important factors that influence the efficiency of the extraction process of phenolic compounds. Preliminary experiments were carried out to evaluate the range of variables for the extraction of phenolic compounds. The conditions of these experiments and the results obtained are listed in Table 1.

As seen in Table 1, the lowest extraction of total phenolic compounds was achieved at the room temperature. Improvement in the extraction was observed, when the temperature was increased up to 80 and $100{ }^{\circ} \mathrm{C}$. On the other hand, the percentage of ethanol, varying between $30-60 \%$, showed similar results. For the time of extraction, the highest concentration of total phenolic compounds (TPC) was obtained at higher extraction periods. However, there were no significant differences between the experiments carried out at 120 and $180 \mathrm{~min}$. The highest total phenolic compounds extraction (2.0, 2.1 and $1.9 \mathrm{~g} \mathrm{GAE} /$ $100 \mathrm{~g}$ VPR) was obtained under conditions of experiment $2\left(30 \%, 80^{\circ} \mathrm{C}\right.$ and $120 \mathrm{~min})$, experiment $4\left(45 \%, 80^{\circ} \mathrm{C}\right.$ and $\left.180 \mathrm{~min}\right)$ and experiment $6\left(45 \%, 100{ }^{\circ} \mathrm{C}\right.$ and $\left.120 \mathrm{~min}\right)$, respectively. The lowest phenolic compounds extraction (1.2 and $1.5 \mathrm{~g} \mathrm{GAE} / 100 \mathrm{~g}$ VPR) was achieved in experiments 7 and 5 (Table 1), respectively. In this preliminary study, it is observed that the temperature is the most important factor for the extraction of polyphenols compounds from vine pruning residue. On the other hand, the time of extraction has a lower influence on the TPC extraction than the ethanol concentration and temperature.

\subsubsection{Total phenolic compounds and antioxidant activity CHE method}

Based on previous results (Table1), an experimental design $\left(2^{3}\right)$ was proposed to optimize the phenolic compounds extraction and to evaluate their antioxidant capacity. The range of operational conditions (temperature, time and percentage of ethanol) and dependent variables studied in this work were listed in Table 2.

The total phenolic compounds obtained by CHE ranged from 1.2 to $2.2 \mathrm{~g} \mathrm{GAE} / 100 \mathrm{~g}$ of VPR. Maximum concentration of total phenolic compounds (2.2 g GAE/ $100 \mathrm{~g}$ ) was obtained under conditions of the central points $\left(120 \mathrm{~min}, 80^{\circ} \mathrm{C}\right.$ and $45 \%$ ethanol concentration) and minimum concentration of total phenolic compounds (1.2 g GAE/ $100 \mathrm{~g})$ was obtained in run $3\left(180 \mathrm{~min}, 60^{\circ} \mathrm{C}\right.$ and $30 \%$ ethanol concentration). These results are in agreement with the values found by other authors (Çetin et al., 2011; Karacabey and Mazza, 2008; LuqueRodríguez et al., 2006; Moreira et al., 2018) for CHE using different ethanol concentrations. Studies in the literature have shown that the total content of phenols in VPR can vary significantly according to the grape variety (Çetin et al., 2011; Delgado-Torre et al., 2012; Farhadi et al., 2016). Previous work confirmed the influence of solvent concentration on the extraction process of phenolic compounds (Alexandru et al., 2014; Moreira et al., 2018). Mixtures of alcohols/water were found to be more efficient in extraction of phenolic constituents than the corresponding mono-component solvent system due to the increase in permeability in the membrane of the lignocellulosic material (Alara et al., 2018; Bouras et al., 2015). However, despite increasing the extraction of total phenolic compounds, it does not have much influence on the antioxidant activity (Pinelo et al., 2006; Spigno et al., 2007; Yilmaz et al., 2006).

The antioxidant activities of the extracts varied, according to the analysis method, between 1.7 and $4.7 \mathrm{~g}$ FE/ $100 \mathrm{~g}$ for the FRAP, 2.9-5.7 and $1.0-2.4 \mathrm{~g} \mathrm{GAE} / 100 \mathrm{~g}$ and $\mathrm{IC}_{50} 0.6-1.3$ and 0.2 to 0.8 , for DPPH and ABTS, respectively. Maximum antioxidant activity for FRAP (4.7 $\mathrm{g} \mathrm{FE}$ / $100 \mathrm{~g}$ ) were obtained under conditions of the central points (120 min, $80^{\circ} \mathrm{C}$ and $45 \%$ ethanol concentration). For the ABTS and DPPH methods, the maximum antioxidant activity was achieved in one of the axial points; runs 10 and 12, respectively, both made using ethanol $45 \%$. The highest antioxidant activity measured by DPPH was $2.4 \mathrm{~g} \mathrm{TE} /$ $100 \mathrm{~g}$ VPR (run 12) and the highest antioxidant activity quantified by ABTS was of $5.7 \mathrm{~g}$ TE/ $100 \mathrm{~g}$ VPR (run 10). The lowest concentration of total phenolic compounds was obtained in the run $3\left(180 \mathrm{~min}, 60^{\circ} \mathrm{C}\right.$ and $30 \%)$. The antioxidant activity of vine pruning extracts was superior to the results obtained by Moreira et al. (2018), for FRAP $(0.72 \mathrm{~g}$ AAE/100 $g$ VPR) and DPPH (0.83 $g$ TE/100 $g$ VPR).

The experimental variables were correlated following the polynomial Eq. 1, of the second order, presented in point 2.2.2. The proposed mathematical models describing the extraction time $\left(x_{1}\right)$, temperature time $\left(x_{2}\right)$ and ethanol concentration $\left(x_{3}\right)$ as function and using normalized values are described by Eqs. $3-5$ and 6 for TPC $\left(y_{1}\right)$, FRAP $\left(y_{2}\right)$, DPPH $\left(y_{3}\right)$ and ABTS $\left(y_{4}\right)$, respectively.

$$
\begin{aligned}
y_{1}= & 2.75+0.11 x_{1}+0.09 x_{1}^{2}+0.08 x_{2}-0.25 x_{2}^{2}-0.35 x_{3}-0.48 x_{3}^{2} \\
& +0.09 x_{1} x_{2}+0.04 x_{1} x_{3}+0.03 x_{2} x_{3} \\
y_{2}= & 4.64+0.11 x_{1}-0.97 x_{1}^{2}+0.04 x_{2}-0.91 x_{2}^{2}-0.61 x_{3}-0.84 x_{3}^{2} \\
& +0.03 x_{1} x_{2}-0.16 x_{1} x_{3}+0.20 x_{2} x_{3} \\
y_{3}= & 2.53+2.25 x_{1}+0.12 x_{1}^{2}+0.03 x_{2}-0.13 x_{2}^{2}-0.12 x_{3}-0.24 x_{3}^{2} \\
& -0.13 x_{1} x_{2}-0.03 x_{1} x_{3}+0.01 x_{2} x_{3} \\
y_{4}= & 4.66+0.24 x_{1}+0.53 x_{1}^{2}+0.12 x_{2}-0.14 x_{2}^{2}-0.17 x_{3}+0.43 x_{3}^{2} \\
& -0.06 x_{1} x_{2}+0.01 x_{1} x_{3}+0.20 x_{2} x_{3}
\end{aligned}
$$

The $R^{2}$ of the models presented in Eqs. 3-6 were: 0.94, 0.90, 0.69 and 0.73 , respectively. The calculated $F$-value $\left(F_{5,3}\right)$ were: 38.35 (Eq. 3 ); 67.21 (Eq. 4); 16.95 (Eq. 5) and 78.16 (Eq. 6). The models were validated by ANOVA analysis and $F$-test at $95 \%$ of confidence level before building the response surface graphs presented in Fig. 1a-d. All models were statistically significant since the calculated $F$-values were higher than the listed $F$-value $\left(F_{5,3}=9.01\right)$ at $95 \%$ of confidence level.

The statistical significance of the model (based on Fischer's $F$ parameter) showed the good fitting of the evaluated variables total phenolics compounds and FRAP $\left(R^{2} \geq 0.9\right)$.

Table 4 shows the regression coefficients and variance analysis of linear, quadratic and interactions between variables. The total phenolic compounds (TPC) and antioxidant activity of VPR extracts presented significant effects $(p<0.05, p<0.01$ or $p<0.0001)$, whereas the interactions between the variables presented different meanings according to the applied analysis method $(p<0.05, p<0.01$ or $p<$ 0.0001). Therefore, the linear and quadratic effects of independent variables were the main determinant terms for antioxidant activities. Fig. 1a-d shows the effect of temperature and extraction time, with a fixed concentration of $45 \%$ ethanol, on the extraction of TPC and antioxidant activity measured by FRAP, DPPH and ABTS. As shown in Fig. 1a, concentration of total phenolic compounds above $2 \mathrm{~g} \mathrm{GAE}$ / $100 \mathrm{~g}$ of VPR was obtained when the temperature was $>80^{\circ} \mathrm{C}$, regardless of the extraction time. The temperature had a notable positive effect on the concentration of total phenolic compounds. Fig. 1b shows the response surface and the Pareto plot of the effects of the two variables, namely extraction time, extraction temperature (ethanol concentration set at 45\%), for FRAP assays. Quadratic and linear effects of the variables were all significant. Control of model parameters, $R^{2}, F$ exp, confirmed the model adequacies for total phenolics compounds and FRAP (Table 4).

The antioxidant activity measured by DPPH, showed significant effects for all variables and their interactions, except for the interaction between the extraction time and the ethanol concentration, but increasing the temperature and extraction time at low ethanol concentrations reduced the antioxidant capacity of the extracts (Fig. 1c). With the increase of the extraction temperature, DPPH values increased significantly. However, no significant differences were found in DPPH when ethanol concentration increased above $45 \%$. The interaction of 
a)
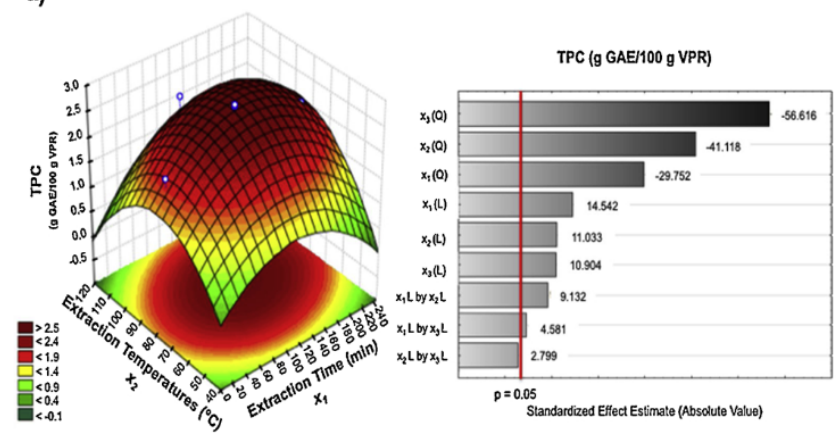

c)

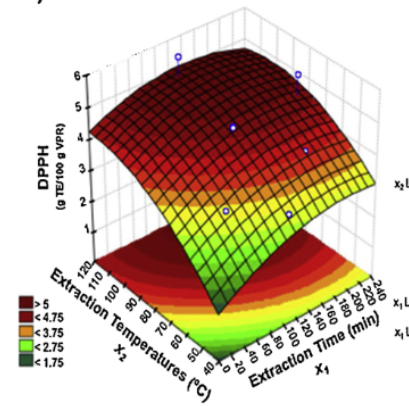

b)

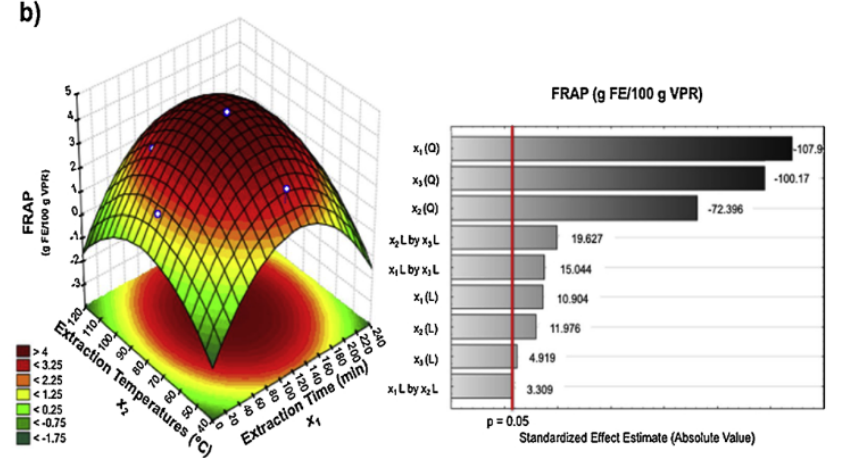

d)

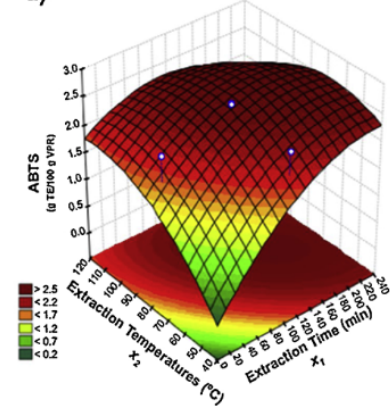

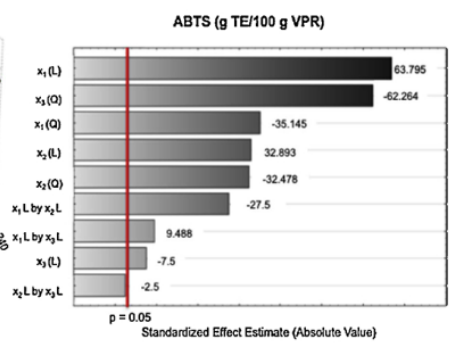

Fig. 1. Pareto diagram for standardized effects and response surface graphs as function of time of extraction and temperature of extraction (fixed enthanol concentraction at $45 \%$ of: a) total phenolicas compounds in GAE $\mathrm{g} / 100 \mathrm{~g}$ and antioxidant activity b) FRAP in $\mathrm{g}$ FE (II) $/ 100 \mathrm{~g}$. c) DPPH in $\mathrm{g}$ TE/100 $\mathrm{g}$ and d) ABTS in $\mathrm{g}$ TE/ $100 \mathrm{~g}(p>0.05)$.

Table 4

Analysis of variance of the regression parameters of the predicted second order polynomial models for total phenol compounds and antioxidant activities (FRAP, DPPH and ABTS).

\begin{tabular}{lllllll}
\hline Coefficientes & $y_{1}$ & $y_{2}$ & $y_{3}$ & $y_{4}$ & $y_{5}$ & $y_{6}$ \\
\hline$\beta_{O i}$ & 2.75 & 4.64 & 2.53 & 4.66 & 0.071 & 0.218 \\
$\beta_{1 i}$ & $0.23^{\mathrm{a}}$ & $0.11^{\mathrm{a}}$ & $2.25^{\mathrm{a}}$ & $0.24^{\mathrm{a}}$ & $-0.002^{\mathrm{a}}$ & $0.001^{\mathrm{d}}$ \\
$\beta_{2 i}$ & $0.18^{\mathrm{b}}$ & $0.97^{\mathrm{a}}$ & $0.12^{\mathrm{a}}$ & $0.53^{\mathrm{b}}$ & $0.011^{\mathrm{a}}$ & $0.031^{\mathrm{a}}$ \\
$\beta_{3 i}$ & $0.17^{\mathrm{b}}$ & $0.04^{\mathrm{b}}$ & $0.03^{\mathrm{a}}$ & $0.12^{\mathrm{a}}$ & $0.006^{\mathrm{a}}$ & $0.056^{\mathrm{a}}$ \\
$\beta_{11 i}$ & $-0.50^{\mathrm{a}}$ & $-0.91^{\mathrm{a}}$ & $-0.13^{\mathrm{a}}$ & $-0.14^{\mathrm{a}}$ & $-0.007^{\mathrm{a}}$ & $-0.025^{\mathrm{a}}$ \\
$\beta_{22 i}$ & $-0.70^{\mathrm{a}}$ & $-0.61^{\mathrm{a}}$ & $-0.12^{\mathrm{a}}$ & $-0.17^{\mathrm{a}}$ & $-0.009^{\mathrm{a}}$ & $-0.040^{\mathrm{a}}$ \\
$\beta_{33 i}$ & $-0.96^{\mathrm{a}}$ & $-0.84^{\mathrm{a}}$ & $-0.24^{\mathrm{a}}$ & $0.43^{\mathrm{a}}$ & $-0.012^{\mathrm{a}}$ & $-0.045^{\mathrm{a}}$ \\
$\beta_{12 i}$ & $0.19^{\mathrm{b}}$ & $0.03^{\mathrm{c}}$ & $-0.13^{\mathrm{a}}$ & $-0.06^{\mathrm{a}}$ & $-0.005^{\mathrm{a}}$ & $0.020^{\mathrm{a}}$ \\
$\beta_{13 i}$ & $0.09^{\mathrm{c}}$ & $-0.16^{\mathrm{a}}$ & $0.03^{\mathrm{d}}$ & $0.01^{\mathrm{b}}$ & $0.006^{\mathrm{a}}$ & $-0.021^{\mathrm{a}}$ \\
$\beta_{23 i}$ & $0.06^{\mathrm{d}}$ & $0.20^{\mathrm{a}}$ & $0.01^{\mathrm{a}}$ & $0.20^{\mathrm{d}}$ & $0.001^{\mathrm{a}}$ & $0.012^{\mathrm{a}}$ \\
$R^{2}$ & 0.94 & 0.90 & 0.69 & 0.73 & 0.74 & 0.90 \\
F-exp & 38.35 & 67.21 & 16.95 & 78.16 & 517.19 & 592.64 \\
lack of fit & $51.36^{\mathrm{a}}$ & $434.36^{\mathrm{a}}$ & $377.60^{\mathrm{a}}$ & $803.74^{\mathrm{a}}$ & $8217.06^{\mathrm{a}}$ & $135.79^{\mathrm{a}}$ \\
\hline
\end{tabular}

\footnotetext{
a Significant coefficients at the $p<0.001$ confidence level.

b Significant coefficients at the $p<0.01$ confidence level.

c Significant coefficients at the $p<0.05$ confidence level.

d not significant $p>0.05$.
}

temperature and ethanol concentration was significant for DPPH method. Fig. 1d shows the effect of time and temperature on the antioxidant activity measured by ABTS. The extraction time presented a linear effect, while the extraction temperature and the ethanol concentration had quadratic effects on the response. Under these conditions, the maximum antioxidant activity measured by ABTS can be obtained with an extraction temperature of $80{ }^{\circ} \mathrm{C}$ and $45 \%$ ethanol. However, the linear effects of the extraction time demonstrate that an increase on the extraction time, lead to higher antioxidant activity, according to the method ABTS. Previous studies with VPR showed a significant linear increase of the antioxidant activity (ABTS), with increase temperature and low ethanol concentrations (50\%). However, the effect of temperature diminished in higher ethanol concentrations
(60\%) (Karacabey and Mazza, 2010). The ethanol concentration, time and temperature on total phenolics compound and antioxidant activities of VPR, has been also reported by Luque-Rodríguez et al. (2006), and Karacabey and Mazza (2010). The authors showed that the only significant variable was the temperature $\left(16.4-240{ }^{\circ} \mathrm{C}\right)$; the percentage of ethanol $(20-100 \%)$ and extraction time $(20-90 \mathrm{~min})$ had negative and positive effects, respectively. The lack of adjustment test at the 0.05 level does not indicate evidence of lack of fit for both the total phenolic compound models and antioxidant activity measured by FRAP, DPPH and ABTS.

\subsubsection{Process optimization and validation}

In the search to find the highest antioxidant activity (using FRAP, DPPH and ABTS methods), and the total polyphenolic content, maintaining the minimum concentration of ethanol, time and temperature, it was possible to optimize the extraction process. The optimal extraction conditions for the present study were different according to the analysis performed. Optimized parameters for antioxidant activities were included in Table 5. As observed, operational conditions to maximize the antioxidant activity for different methods varied in the range of $80-115{ }^{\circ} \mathrm{C}, 137-175 \mathrm{~min}$ and $45-53 \%$ of ethanol concentration. The antioxidant activities, measured by FRAP, ABTS and total phenolic compounds showed similar optimal conditions between them, temperature of 80 to $83{ }^{\circ} \mathrm{C}$ and ethanol concentration of 45 to $46 \%$, however the extraction time ranged from 124 to $175 \mathrm{~min}$, where the potential values were $4.4 \mathrm{~g}$ FE/ $100 \mathrm{~g}$ VPR, $2.5 \mathrm{~g}$ TE/ $100 \mathrm{~g}$ VPR and $2.3 \mathrm{~g}$ $\mathrm{GAE} / \mathrm{g}$, respectively. For DPPH the optimum conditions were: extraction time of $147 \mathrm{~min}$, temperature of $115^{\circ} \mathrm{C}$ and ethanol concentration of $53 \%$, where the antioxidant potential value was $5.1 \mathrm{~g}$ TE/ $100 \mathrm{~g}$ VPR. The validation experiments carried out under the predicted conditions derived from the experimental design analysis demonstrated that the experimental values were close to the predicted values, confirming the validity and adequacy of the predicted models. In addition, the verification experiments also proved that the predicted values of total polyphenolic compounds and antioxidant activity (using FRAP method) 
Table 5

Optimized conditions for antioxidant activity of vine pruning residue extract (including predicted and experimental values).

\begin{tabular}{|c|c|c|c|c|c|}
\hline \multirow[t]{2}{*}{ Responses } & \multicolumn{3}{|c|}{ Process variables } & \multirow[t]{2}{*}{ Predicted value } & \multirow[t]{2}{*}{ Experimental value } \\
\hline & $\mathrm{X}_{1}(\mathrm{~min})$ & $\mathrm{X}_{2}\left({ }^{\circ} \mathrm{C}\right)$ & $\mathrm{X}_{3}(\% \mathrm{v} / \mathrm{v})$ & & \\
\hline TPC (g GAE/100 g) & 137 & 83.45 & 46.68 & 2.26 & $2.27 \pm 0.15$ \\
\hline FRAP ( $\mathrm{g} \mathrm{FeE} / 100 \mathrm{~g}$ ) & 124 & 81.72 & 45.42 & 4.38 & $4.45 \pm 0.24$ \\
\hline DPPH (g TE/100 g) & 147 & 115.33 & 53.39 & 5.22 & $5.12 \pm 0.24$ \\
\hline ABTS ( $\mathrm{g}$ TE/100 g) & 175 & 80.01 & 45.06 & 2.37 & $2.54 \pm 0.13$ \\
\hline
\end{tabular}

for the VPR model can be satisfactorily achieved within the $95 \%$ confidence interval. Therefore, the regression equations obtained in this study can be used to obtain extracts with optimal antioxidant activity and total polyphenols.

\subsubsection{UHPLC analysis of phenolic compounds of CHE}

Qualitative and quantitative analysis of phenolic compounds of the extract at optimized condition were analyzed by ultra high performance liquid chromatography (UHPLC). Table 6 lists the concentrations of the identified compounds (results expressed in $\mathrm{mg} / 100 \mathrm{~g}$ of VPR). The highest concentration of phenolic compounds was obtained under conditions of the central point of experimental design $\left(120 \mathrm{~min}, 80^{\circ} \mathrm{C}\right.$ and $45 \%$ ). Fifteen phenolic compounds of different classes were detected: flavonoids, phenolic acids and stilbenes, the concentrations of the compounds varied according to the extraction conditions applied in each experiment. The flavonoids present in the extracts obtained were catechin (12.7-21 mg/100 g), narigenin (4.9-6.2 mg/100 g), apigenin $(6.4-218.0 \mathrm{mg} / 100 \mathrm{~g})$, quercetin $(23.5-27.7 \mathrm{mg} / 100 \mathrm{~g})$ and rutin $(9-16.5 \mathrm{mg} / 100 \mathrm{~g})$. The phenolics acids obtained were rosmarinic acid (13.5-15.3 mg/100 g), cinnamic acid (12.6-16.1 mg/100 g), syringic acid (13.5-20 mg/100 g), vanillic acid (19.7-23.1 mg/100 g), ferulic acid $(5.8-6.9 \mathrm{mg} / 100 \mathrm{~g})$, gallic acid $(6.3-12.4 \mathrm{mg} / 100 \mathrm{~g})$, $o$-cumaric acid $(7.4-16 \mathrm{mg} / 100 \mathrm{~g})$ and ellagic acid $(5.0-75.5 \mathrm{mg} / 100 \mathrm{~g})$. The retention time of the epicatechin and the p-coumaric acid were the same and it was not possible to separate these compounds, so the concentrations are presented together $(5.3-6.7 \mathrm{mg} / 100 \mathrm{~g})$. The stilbene resveratrol was found in concentrations between $13.3 \mathrm{mg}$ and $14.9 \mathrm{mg} /$ $100 \mathrm{~g}$ VPR.

The most abundant flavonoids in VPR are (+) - catechin and (-) epicatechin, however, in this work these compounds were not the most abundant which is not in accordance with previous studies (Çetin et al., 2011; Delgado-Torre et al., 2012; Luque-Rodríguez et al., 2006; Sánchez-Gómez et al., 2017b, 2014). The highest concentration of (+) catechin was $21.5 \mathrm{mg} / 100 \mathrm{~g}$ of VPR (run $6,60 \mathrm{~min}, 100^{\circ} \mathrm{C}$ and $60 \%$ of ethanol). The highest content of $p$-coumaric acid + epicatechin $6.7 \mathrm{mg} /$ $100 \mathrm{~g}$ of VPR, was found at run $10\left(221 \mathrm{~min}, 80^{\circ} \mathrm{C}\right.$ and $45 \%$ of ethanol). The highest concentration of resveratrol obtained in this study was $14.9 \mathrm{mg} / 100 \mathrm{~g}$ of VPR $\left(221 \mathrm{~min}, 80^{\circ} \mathrm{C}\right.$ and $\left.45 \%\right)$. These values were higher than those found by Sánchez-Gómez et al. (2014) in extracts of VPR $(2.8 \mathrm{mg} / 100 \mathrm{~g})$. But, the values of resveratrol concentration were lower than those reported for VPR hydroethanolic extracts (Cebrián et al., 2017; Soural et al., 2015; Vergara et al., 2012). However, in this work the most abundant flavonoid was apigenin with $207.9 \mathrm{mg} / 100 \mathrm{~g}$ of VPR ( $120 \mathrm{~min}, 80^{\circ} \mathrm{C}$ and $45 \%$ ), although it has not been reported in previous studies using VPR. However, apigenin was identified in extracts of grape marc (Pintać et al., 2018).

The concentrations of phenolic acids: gallic acid, vanillic acid, syringic acid and ferulic acid were within the range (0.5-2.1, 0.3-0.8, 0.6 and $0.2-14.3 \mathrm{mg} / 100 \mathrm{~g}$, respectively) reported in literature (Cebrián et al., 2017; R. Sánchez-Gómez et al., 2017b, 2014). Among the identified phenolic acids, the most abundant in VPR extracts was ellagic acid, with concentration of $68.6 \mathrm{mg} / 100 \mathrm{~g}$ VPR at the central point ( $120 \mathrm{~min}, 80^{\circ} \mathrm{C}$ and $45 \%$ ), these values were higher than those found in the literature Cebrián et al. (2017) (1.36-2.1 mg/100 g VPR), LuqueRodríguez et al. (2006) (17.9-57 mg/100 g VPR), Sánchez-Gómez et al. (2017b) (0.8-5.4 mg / 100 g VPR), Sánchez-Gómez et al. (2014) (0.4-1.4 mg/100 g VPR). As a general trend, the total concentration of phenolic compounds in the extract, identified by UHPLC, increased with temperature. According to Luque-Rodríguez et al. (2006), the temperature was the most influential variable on the composition of the extracts of VPR, whereas the percentage of ethanol and extraction time had only an influence on the amount of each compound.

Ellagic acid is a polyphenol of great interest due to its high prebiotic, antioxidant and anti-inflammatory activity (García-Niño and Zazueta, 2015; Landete, 2011; Yu-Qing et al., 2017). In addition, ellagic acid was one of the most abundant compounds found in VPR extracts from this study. The ellagic acid content in extracts of VPR obtained using CHE ranged from 5.0 to $75.5 \mathrm{mg} / 100 \mathrm{~g}$ VPR. The results obtained in this work were superior to those described in previous works for the ellagic acid content in extracts of VPR obtained using the CHE technique (Cebrián et al., 2017; Luque-Rodríguez et al., 2006; SánchezGómez et al., 2017b, 2014). According to our results, the highest ellagic acid content was achieved using $45 \%$ ethanol, temperature of $80{ }^{\circ} \mathrm{C}$ and extraction time of $120 \mathrm{~min}$. On the other hand, the lowest content was obtained in the extract prepared using $60 \%$ ethanol, extraction temperature of $60^{\circ} \mathrm{C}$ and $60 \mathrm{~min}$ of extraction time. Fig. 2a shows the response surface for the temperature-time relationship with the ethanol concentration set at $45 \%$ for the extraction of ellagic acid. All extraction parameters investigated showed a significant positive impact on the final ellagic acid content (Fig. 2b). The concentration of ethanol showed the greatest positive impact on ellagic acid content in VPR extracts. The levels of ethanol, extraction temperature and extraction time significantly affected the ellagic acid content $(p<0.001)$ (Table 4). The interactions between time/ethanol concentration, time/temperature and temperature/ethanol concentration, $(p<0.001)$ also significantly affected the ellagic acid content.

The final predictive equation to describe the extraction efficiency to reach the maximum ellagic acid content $\left(y_{5}\right)$ of VPR is as follows:

$$
\begin{aligned}
y_{5}= & 0.07-0.002 x_{1}+0.011 x_{1}^{2}+0.006 x_{2}-0.007 x_{2}^{2}-0.009 x_{3} \\
& -0.012 x_{3}^{2}-0.005 x_{1} x_{2}-0.006 x_{1} x_{3}+0.001 x_{2} x_{3}
\end{aligned}
$$

According to the $p$-value, it can be concluded that the model showed a good approximation for the investigated responses $(p<0.001)$. The $R^{2}$ for ellagic acid was 0.74 , the non-significant value of lack of fit ( $F$ $=135.79$ ) showed the model is fitted to the spatial influence of the variables to the response with good prediction, with a F-value of 517.19, higher than the $F$-value table $\left(F_{5.3}=9.01\right)$.

The content of apigenin in VPR extracts obtained using CHE ranged from 6.4 to $2.2 \mathrm{mg} / 100 \mathrm{~g}$ VPR. In our study, the extract with the highest apigenin content was obtained using the following parameters: $45 \%$ ethanol, temperature of $80^{\circ} \mathrm{C}$ and extraction time of $120 \mathrm{~min}$. However, it was not identified using $60 \mathrm{~min}$ of extraction time, extraction temperature of $60{ }^{\circ} \mathrm{C}$ and $30 \%$ of ethanol. The lowest content was obtained in the extract prepared using $180 \mathrm{~min}, 60^{\circ} \mathrm{C}$ and $30 \%$ ethanol. The results show that the concentration of apigenin increased up to $80^{\circ} \mathrm{C}$ and 120 min of extraction, at higher temperatures and times there was a decrease of the concentration, probably due to its degradation. The response surface shows the interaction of the extraction time and temperature with the ethanol concentration set at $45 \%$ (Fig. 2a). The 
Pareto graph (Fig. 2d) showed that the most dominant factor influencing the extraction of apigenin was the concentration of ethanol, and this factor positively affected its extraction $(p<0.001)$. The quadratic and linear levels of extraction temperature, quadratic extraction time and the interactions between time/temperature, time/ethanol concentration and temperature/ethanol concentration also significantly altered the apigenin content, while the linear parameter of extraction time was insignificant $(p>0.5)$ (Table 4). The predictive equation to describe the extraction efficiency to reach the maximum apigenin content $\left(y_{6}\right)$ of VPR is as follows:

$$
\begin{aligned}
y_{6}= & 0.21+0.001 x_{1}+0.0001 x_{1}^{2}+0.031 x_{2}+0.056 x_{2}^{2}-0.025 x_{3} \\
& -0.039 x_{3}^{2}-0.045 x_{1} x_{2}+0.020 x_{1} x_{3}+0.021 x_{2} x_{3}
\end{aligned}
$$

The variance analysis (ANOVA) was able to confirm that the model was significant $(p<0.001)$, and with $R^{2}$ values of 0.90 and calculated F-value 592.64 higher than the table $F_{5,3}=9.01-95 \%$ of confidence level (Table 4). Negligible lack of fit $(p>0.05)$ was also evidence of good fit of the model.

\subsection{Microwave-assisted extraction (MAE)}

Based on the optimization of the conventional extraction method, study of the extraction of the polyphenolic compounds using microwave-assisted method was initiated in order to find the minimum conditions of extraction (concentration of ethanol (\%), temperature $\left({ }^{\circ} \mathrm{C}\right.$ ) and time)) to obtain maximum extraction yield. The experiments were conducted at different concentrations of ethanol (0-60\%), temperatures $\left(60-120^{\circ} \mathrm{C}\right)$ and time $(5-40 \mathrm{~min})$.

\subsubsection{Total phenolic compounds and antioxidant activity MAE method}

According to Rombaut et al. (2014); Vinatoru et al. (2017) from an industrial point of view, the conventional extraction technique has some disadvantages, such as insufficient recovery of extracts, extensive extraction time and intensive heating and/or mixing, resulting in high energy consumption. In contrast MAE is a more advantageous methodology with its selective heating of the vegetal material versus solvent that improves the extraction mechanism by increasing the extraction yield and decreasing the extraction time. The predicted optimum conditions for TPC extraction were calculated as extraction time of $137 \mathrm{~min}$, extraction temperature of $83.45^{\circ} \mathrm{C}$, ethanol concentration $46.7 \%$, and the model predicted a maximum TPC concentration of $2.3 \mathrm{~g}$ $\mathrm{GAE} / 100 \mathrm{~g}$ VPR. The experimental concentration achieved under these conditions was similar CHE $2.3 \mathrm{~g} \mathrm{GAE} / 100 \mathrm{~g}$ VPR. For MAE the total phenolic content concentrations ranged between 1.5 and $2.4 \mathrm{~g}$ GAE/ $100 \mathrm{~g}$ VPR. The total phenolic content (TPC) as function of the extraction conditions are shown on Table 3 . The results showed that the highest concentration of TPC was reached using $30 \%$ ethanol, $120{ }^{\circ} \mathrm{C}$ and $5 \mathrm{~min}$ for MAE. According to these results, MAE can be considered a better method for polyphenols extraction $(2.4 \pm 0.01 \mathrm{~g} \mathrm{GAE} / 100 \mathrm{~g}$ VPR) than the conventional heating extraction (CHE) $(2.2 \pm 0.1 \mathrm{~g}$ $\mathrm{GAE} / 100 \mathrm{~g}$ VPR). In addition, the antioxidant capacity of extracts obtained by MAE was significantly higher than the obtained by CHE. These values are in agreement with the results obtained by Çetin et al. (2011) (2.5 to $3.6 \mathrm{~g} \mathrm{GAE} / 100 \mathrm{~g}$ VPR) and were superior to those found by Cebrián et al., and Karacabey and Mazza, $(2017$; 2008) $(0.1$ to 0.2 and 0.3 to $0.8 \mathrm{~g} \mathrm{GAE} / 100 \mathrm{~g}$ VPR, respectively). The superheated extraction of ethanol and water from VPR polyphenols yielded 1.7 to $4.1 \mathrm{~g}$ of GAE $/ 100 \mathrm{~g}$, depending on the experimental parameters. Experiments 15 and $16\left(0 \%\right.$ ethanol, $120^{\circ} \mathrm{C}, 10 \mathrm{~min}$. and $0 \%$ ethanol, $120^{\circ} \mathrm{C}$, $40 \mathrm{~min}$.) showed lower quantities of phenolic compounds in comparison to the other extractions using the same times and temperatures. This is due to the higher dielectric constant $(\varepsilon=80)$ that water has in comparison to other solvents. This feature causes significantly lower dissipation than other solvents $(\delta=1500 \times 104)$. This phenomenon causes overheating of the water leading to degradation of the bioactive 


\section{a)}
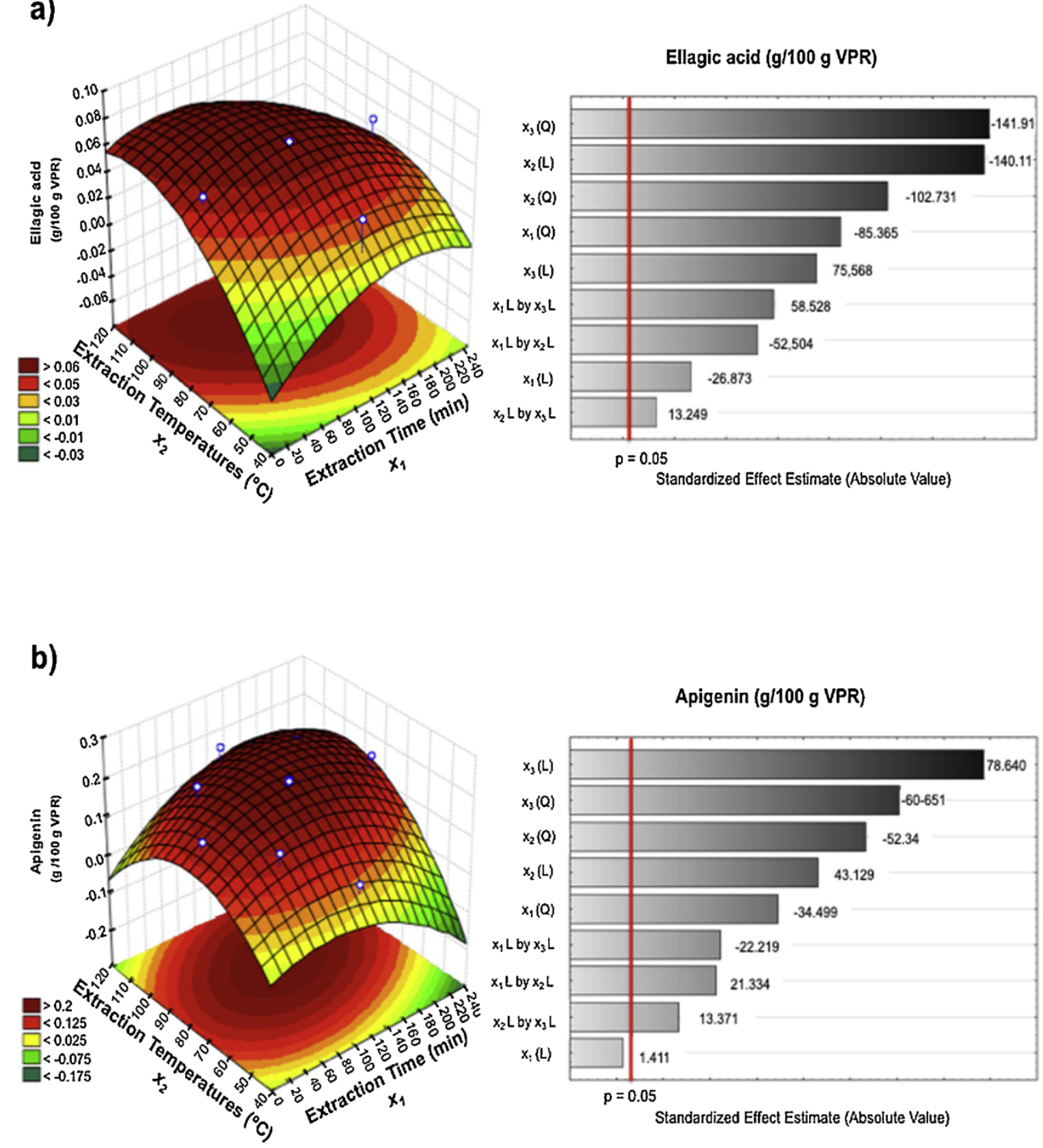

Fig. 2. Response surface and Pareto diagram for standardized effects showing the effect of temperature and time of extraction (fixed enthanol concentraction at $45 \%$ of: a) total phenolicas compounds in GAE $g / 100 \mathrm{~g}$ and antioxidant activity b) FRAP in $\mathrm{g}$ FE (II)/100 $\mathrm{g}$ c) DPPH in $\mathrm{g}$ TE/100 $\mathrm{g}$ and d) ABTS in $\mathrm{g}$ TE/100 $\mathrm{g}(p>0.05)$.

compounds (Proestos and Komaitis, 2008).

The FRAP, DPPH and ABTS assays are often used to determine the total antioxidant activities of natural compounds (Oroian and Escriche, 2015). The antioxidant activities FRAP, DPPH and ABTS ranged from 4.1 to $9.5 \mathrm{~g} \mathrm{FE}$ (II)/100 $\mathrm{g}$ VPR, 2.3 to $4.3 \mathrm{TE} / 100 \mathrm{~g}$ VPR and 2.2 to $3.4 \mathrm{~g}$ TE/100 $g$ VPR, respectively (Table 3 ). The extracts that presented lower TPC concentrations were not submitted to $\mathrm{IC}_{50}$ inhibition analysis for DPPH and ABTS antioxidant activities. The highest antioxidant capacity measured by FRAP using MAE method was $9.5 \mathrm{~g}$ TE/ $100 \mathrm{~g}$ VPR using $60 \%$ ethanol at $120^{\circ} \mathrm{C}$ for $40 \mathrm{~min}$, these results were superior to those found in this work using the CHE method and that is in contrast to that described by (Gullón et al., 2017). These authors tested different severities in autohydrolysis for the extraction of VPR phenolic compounds. They described FRAP values between 0.7 and $2.7 \mathrm{~g}$ TE/100 $\mathrm{g}$ VPR. The results of ABTS radical censor sequestering activity were consistent with the DPPH tests, and showed moderate oxidant activity relative to ABTS. The highest antioxidant activity was measured by DPPH and ABTS methods (4.3 TE/100 $\mathrm{g}$ of VPR and $3.4 \mathrm{~g}$ TE/ $/ 100 \mathrm{~g}$ of VPR, respectively), using $60 \%$ ethanol, at $120^{\circ} \mathrm{C}$, during $5 \mathrm{~min}$. The ABTS results were in accordance with those obtained by Karacabey and Mazza (2010) in conventional extractions using a temperature of $83.6{ }^{\circ} \mathrm{C}$, solvent to solid ratio of $70(\mathrm{~mL} / \mathrm{g}$ ) and $58 \%$ ethanol. The antioxidant activities $\left(\mathrm{IC}_{50}\right.$ ) of the VPR extracts obtained by MAE varied from (DPPH) $\mathrm{IC}_{50}=3.6$ to $6.9 \mathrm{~g} / \mathrm{L}$ and (ABTS) $\mathrm{IC}_{50}=1.1$ to $4.0 \mathrm{~g} / \mathrm{L}$, respectively. These values show high efficiency as DPPH and ABTS reducers compared to those obtained by the CHE method $\left(\mathrm{IC}_{50}=4.9\right.$ to $13 \mathrm{~g} / \mathrm{L}, \mathrm{IC}_{50}=2.1$ to $8.1 \mathrm{~g} / \mathrm{L}$, respectively). The greater ability to reduce DPPH and ABTS obtained in MAE was when $30 \%$ ethanol was used at a temperature of $120^{\circ} \mathrm{C}$ for $5 \mathrm{~min}\left(\mathrm{IC}_{50}=3.6 \mathrm{~g} / \mathrm{L}\right.$ and $1.1 \mathrm{~g} / \mathrm{L}$, respectively). According to Ruiz-Moreno et al. (2015) the direct comparison of the antioxidant activities of wine derivatives with the literature is difficult due to the grape variety discrepancy and the variety 
of extractive techniques and quantification methods.

\subsubsection{UHPLC analysis of phenolic compounds of MAE}

Among the 15 polyphenolics compounds identified in the extraction by the CHE method, only 12 compounds were identified in the extracts obtained by the MAE method. The major phenolic compounds identified by UHPLC for MAE were catechin, narigenin, apigenin, rutin, $p$ cumaric acid + epicatechin, ferulic acid, gallic acid, syringic acid, vanillic acid, o-coumaric acid, ellagic acid, cinnamic acid, rosmarinic acid, trans-resveratrol (Table 7). The presence of these compounds is in agreement with other authors (Cebrián et al., 2017; Çetin et al., 2011; Delgado-Torre et al., 2012; Jesus et al., 2017; Sánchez-Gómez et al., 2017b, 2014).

Among the quantified phenolic compounds, the most abundant flavonoids were apigenin (9.4-184 mg/100 $\mathrm{g}$ of VPR) and catechin (16.6-27.1 mg/100 g of VPR), their concentration varied according to the extraction conditions. The concentration of apigenin significantly exceeded the other flavonoids, with the highest concentration of $184 \mathrm{mg} / 100 \mathrm{~g}$ of VPR with $60 \%$ ethanol at $90{ }^{\circ} \mathrm{C}$ for $5 \mathrm{~min}$. Meanwhile, this value was lower than the optimum obtained in CHE, $207.9 \mathrm{mg} /$ $100 \mathrm{~g}$ of VPR ( $120 \mathrm{~min}, 80^{\circ} \mathrm{C}$ and $45 \%$ ). Pintać et al. (2018) was able to extract between 0.30 and $9.1 \mathrm{mg} / 100 \mathrm{~g}$ of grape pomace apigenin, using CHE and $80 \%$ ethanol and acetone as extraction solvents, respectively. The highest concentration of catechin was $27.1 \mathrm{mg} / 100 \mathrm{~g}$ of VPR. The results obtained by MAE for catechin are in agreement with previous studies on extracts of grapevine shoots (Sánchez-Gómez et al., 2017b).

Stilbenes are the most studied group of compounds in VPR due to their important properties for the pharmaceutical industry (Guerrero et al., 2016; Piñeiro et al., 2017, 2016; Shen et al., 2009; Soural et al., 2015). Resveratrol is the most studied stilbene in VPR, in this study the resveratrol concentration ranged from 0.3 to $36.0 \mathrm{mg} / 100 \mathrm{~g}$ of VPR in the MAE method. The highest content of resveratrol was $36.0 \mathrm{mg} / 100 \mathrm{~g}$ of VPR when $60 \%$ ethanol was used at $120^{\circ} \mathrm{C}$ for $5 \mathrm{~min}$. These results are superior to those found by Çetin et al. (2011) and Sánchez-Gómez et al. (2014), in extracts of VPR, but still inferior to the results obtained by Delgado-Torre et al. (2012) using $1 \mathrm{~g}$ of solid and $20 \mathrm{~mL}$ of ethanol of $80 \%(\mathrm{v} / \mathrm{v})$, Soural et al. (2015) $1.5 \mathrm{~g}$ of grape canes and $100 \mathrm{~mL}$ of methanol and Vergara et al. (2012) using $2 \mathrm{~g}$ of solid and $16 \mathrm{~mL}$ of ethanol of $80 \%(\mathrm{v} / \mathrm{v})$, both used higher amounts of solid and organic solvent in a higher concentration than the one used in this work.

The most abundant phenolic acids were ellagic acids (6.67-185.1 mg/100 g of VPR), syringic (15.6-24.4 mg/100 g of VPR) and rosmarinic (15.87-36.25 mg/100 g of VPR). The highest concentration of syringic acid ( $24.4 \mathrm{mg} / 100 \mathrm{~g}$ of VPR) was obtained when using $60 \%$ ethanol at $60{ }^{\circ} \mathrm{C}$ for $10 \mathrm{~min}$ and $20.02 \mathrm{mg} / 100 \mathrm{~g}$ VPR, this concentration was higher than that obtained by CHE when submitted $30 \%$ ethanol at $60{ }^{\circ} \mathrm{C}$ for $60 \mathrm{~min}$. These results are superior to those described in the literature (Cebrián et al., 2017; Sánchez-Gómez et al., 2014). Extracts submitted to $60 \%$ ethanol, at $120^{\circ} \mathrm{C}$ for $5 \mathrm{~min}$, achieved the highest ellagic acid extraction ( $185.1 \mathrm{mg} / 100 \mathrm{~g}$ of VPR) and rosmarinic acid $(36.2 \mathrm{mg} / 100 \mathrm{~g}$ of VPR). These results were superior to those obtained by CHE ( 8.6 and $14.1 \mathrm{mg} / 100 \mathrm{~g}$ of VPR, respectively) using $45 \%$ ethanol at $80^{\circ} \mathrm{C}$ for $120 \mathrm{~min}$. The ellagic acid content varies remarkably according to the solvent and/or the extraction procedure used (Cebrián et al., 2017; Luque-Rodríguez et al., 2006; SánchezGómez et al., 2014).

The experiments that presented the highest concentration of phenolic compounds were 3 and $4\left(60 \%\right.$ ethanol, $120^{\circ} \mathrm{C}$ for $10 \mathrm{~min}$ and $60 \%$ ethanol, $120^{\circ} \mathrm{C}$ for $5 \mathrm{~min}$, respectively). The mixture of organic solvent and water is more efficient in the extraction of phenolic compounds than pure solvents Bouras et al. (2015). According to the results of Liazid et al. (2007), most phenolic compounds can be extracted without degradation at temperatures up to $125^{\circ} \mathrm{C}$ for an extraction time of $20 \mathrm{~min}$. The results obtained for the polyphenolic profile indicate that the concentration of each compound determined after the

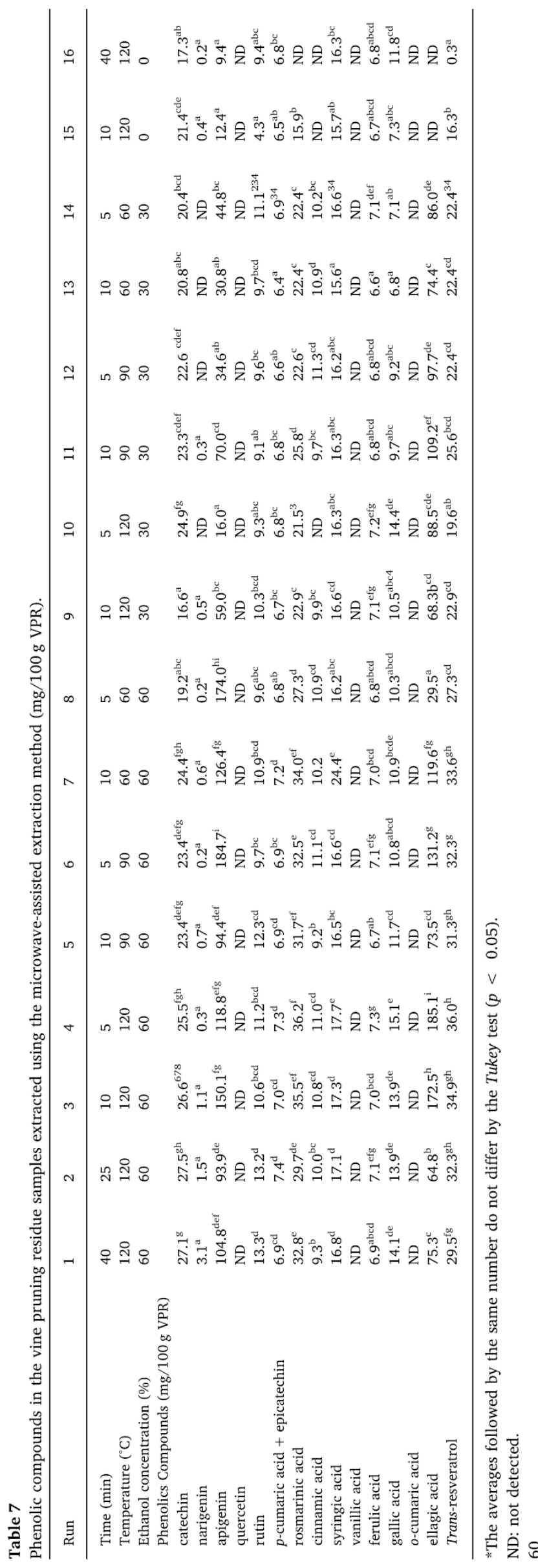


extraction with the different concentrations of ethanol, time and temperature increased significantly using microwaves in comparison with the conventional extraction, except for some compounds (apigenin, cinnamic acid, resveratrol, rutin, rosmarinic acid, ellagic acid, quercetin, vanillic acid and $o$-cumaric acid) and especially for the water extraction, possibly due to the higher dielectric constant. The obtained results are in accordance with Chemat et al. (2017), concluding that, compared to CHE, the MAE is a greener method, as it uses less energy, shorter extraction time and less percentage of ethanol.

Even though, MAE has been successfully used in the extraction of valuable components in laboratory scale, the number of industrial-scale applications remain very small. However, MAE is considered a key process for the application of the biorefinary concept to any industrial production, like is the extraction of natural products (Vinatoru et al., 2017).

\section{Conclusions}

The extraction of polyphenolic compounds (TPC) was optimized for conventional heating and microwave-assisted extraction using environmentally friendly solvents i.e. ethanol and water. The obtained TPC and antioxidant activity were according to the predicted by the linear and quadratic models developed from the optimization study. Extraction of TPC from VPR had greater efficiency when using MAE than CHE methodology. The use of MAE significantly reduced the extraction time and improved the extraction efficiency of TPC of high industrial interest such as ellagic acid and apigenin. The extraction of valuable TPC from VPR contributes to increase the integral valorization of this residue. For first time was reported the presence of the compound apigenin in the extracts of VPR. MAE generally increased extraction of ellagic acid, trans-resveratrol, rosmarinic acid, cinnamic acid and catechin when compared to CHE; similar values were obtained for p-coumaric acid + epicathechin, apigenin, rutin, syringic, ferulic and gallic acid. Lower amounts of naringin, quercetin, vanillic and $o$-cumaric acids were detected in MAE than in CHE.

\section{Acknowledgments}

This study was supported by the Portuguese Foundation for Science and Technology (FCT) under the scope of the strategic funding of UID/ BIO/04469/2019 unit and BioTecNorte operation(NORTE-01-0145FEDER-000004) funded by the European Regional Development Fund under the scope of Norte2020 - Programa Operacional Regional do Norte. Meirielly S. Jesus thanks her fellowship supported by the International Cooperation Program $\mathrm{CNPq} / \mathrm{CSF}$ at the University of Minho financed by CNPq-Brazilian Federal Agency. Zlatina Genisheva and Ricardo Pereira thank to FCT for the financial support (Ref. SFRH/ BPD/108868/2015 and SFRH/BPD/81887/2011, respectively).

\section{References}

Ahmad Mir, S., Ahmad Masoodi, F., Raja, J., 2017. Influence of natural antioxidants on microbial load, lipid oxidation and sensorial quality of rista-A traditional meat product of India. Food Biosci. 20, 79-87.

Alara, O.R., Abdurahman, N.H., Olalere, O.A., 2018. Optimization of microwave-assisted extraction of flavonoids and antioxidants from Vernonia amygdalina leaf using response surface methodology. Food Bioprod. Process. 107, 36-48.

Alexandru, L., Binello, A., Mantegna, S., Boffa, L., Cravotto, G., 2014. Efficient green extraction of polyphenols from post-harvested agro-industry vegetal sources in Piedmont. Comptes Rendus Chim. 17, 212-217.

Ballesteros, L.F., Cerqueira, M.A., Teixeira, J.A., Mussatto, S.I., 2015. Characterization of polysaccharides extracted from spent coffee grounds by alkali pretreatment. Carbohydr. Polym. 127, 347-354.

Bouras, M., Chadni, M., Barba, F.J., Grimi, N., Bals, O., Vorobiev, E., 2015. Optimization of microwave-assisted extraction of polyphenols from Quercus bark. Ind. Crops Prod. 77, 590-601.

Buratti, C., Barbanera, M., Lascaro, E., 2015. Ethanol production from vineyard pruning residues with steam explosion pretreatment. Environ. Prog. Sustain. Energy 34, 802-809.

Calinescu, I., Lavric, V., Asofiei, I., Gavrila, A.I., Trifan, A., Ighigeanu, D., Martin, D.,
Matei, C., 2017. Microwave assisted extraction of polyphenols using a coaxial antenna and a cooling system. Chem. Eng. Process. Process Intensif. 122, 373-379.

Cebrián, C., Sánchez-Gómez, R., Salinas, M.R., Alonso, G.L., Zalacain, A., 2017. Effect of post-pruning vine-shoots storage on the evolution of high-value compounds. Ind. Crops Prod. 109, 730-736.

Çetin, E.S., Altinöz, D., Tarçan, E., Göktürk Baydar, N., 2011. Chemical composition of grape canes. Ind. Crops Prod. 34, 994-998.

Chemat, F., Rombaut, N., Meullemiestre, A., Turk, M., Perino, S., Fabiano-Tixier, A.S., Abert-Vian, M., 2017. Review of green food processing techniques. Preservation, transformation, and extraction. Innov. Food Sci. Emerg. Technol.

Dávila, I., Gordobil, O., Labidi, J., Gullón, P., Dávila, I., Gordobil, O., Labidi, J., Gullón, P., Dávila, I., Gordobil, O., Labidi, J., Gullón, P., 2016. Assessment of suitability of vine shoots for hemicellulosic oligosaccharides production through aqueous processing. Bioresour. Technol. 211, 636-644.

Delgado-Torre, M.P., Ferreiro-Vera, C., Priego-Capote, F., Pérez-Juan, P.M., Luque De Castro, M.D., 2012. Comparison of accelerated methods for the extraction of phenolic compounds from different vine-shoot cultivars. J. Agric. Food Chem. 60, 3051-3060.

Domínguez-Perles, R., Teixeira, A.I.I., Rosa, E., Barros, A.I.I., 2014. Assessment of (poly) phenols in grape (Vitis vinifera L.) stems by using food/pharma industry compatible solvents and response surface methodology. Food Chem. 164, 339-346.

Farhadi, K., Esmaeilzadeh, F., Hatami, M., Forough, M., Molaie, R., 2016. Determination of phenolic compounds content and antioxidant activity in skin, pulp, seed, cane and leaf of five native grape cultivars in West Azerbaijan province, Iran. Food Chem. 199, 847-855.

Galanakis, C.M., Markouli, E., Gekas, V., 2013. Recovery and fractionation of different phenolic classes from winery sludge using ultrafiltration. Sep. Purif. Technol. 107, 245-251.

García-Niño, W.R., Zazueta, C., 2015. Ellagic acid: pharmacological activities and molecular mechanisms involved in liver protection. Pharmacol. Res. 97, 84-103.

Guerrero, R.F., Biais, B., Richard, T., Puertas, B., Waffo-Teguo, P., Merillon, J.-M., CantosVillar, E., 2016. Grapevine cane's waste is a source of bioactive stilbenes. Ind. Crops Prod. 94, 884-892.

Gullón, B., Eibes, G., Moreira, M.T., Dávila, I., Labidi, J., Gullón, P., 2017. Antioxidant and antimicrobial activities of extracts obtained from the refining of autohydrolysis liquors of vine shoots. Ind. Crops Prod. 107, 105-113.

Jesus, M.S., Romaní, A., Genisheva, Z., Teixeira, J.A., Domingues, L., 2017. Integral valorization of vine pruning residue by sequential autohydrolysis stages. J. Clean. Prod. $168,74-86$.

Jing, C.L., Dong, X.F., Tong, J.M., 2015. Optimization of ultrasonic-assisted extraction of flavonoid compounds and antioxidants from alfalfa using response surface method. Molecules 20, 15550-15571.

Karacabey, E., Mazza, G., 2008. Optimization of solid-liquid extraction of resveratrol and other phenolic compounds from milled grape canes (Vitis vinifera). J. Agric. Food Chem. 56, 6318-6325.

Karacabey, E., Mazza, G., 2010. Optimisation of antioxidant activity of grape cane extracts using response surface methodology. Food Chem. 119, 343-348.

Kazibwe, Z., Kim, D.H., Chun, S., Gopal, J., 2017. Ultrasonication assisted ultrafast extraction of Tagetes erecta in water: cannonading antimicrobial, antioxidant components. J. Mol. Liq. 229, 453-458.

Lachman, J., Kotikova, Z., Hejtmankova, A., Pivec, V., Psenienaja, O., Sulc, M., Stoalkova, R., Didina, M., 2016. Resveratrol and piceid isomers concentrations in grapevine shoots, leaves, and tendrils. Hortic. Sci. 43, 25-32.

Landete, J.M., 2011. Ellagitannins, ellagic acid and their derived metabolites: a review about source, metabolism, functions and health. Food Res. Int. 44, 1150-1160.

Liazid, A., Palma, M., Brigui, J., Barroso, C.G., 2007. Investigation on phenolic compounds stability during microwave-assisted extraction. J. Chromatogr. A 1140, 29-34.

Luque-Rodríguez, J.M., Pérez-Juan, P., Luque de Castro, M.D., 2006. Extraction of polyphenols from vine shoots of Vitis vinifera by superheated ethanol - water mixtures. J. Agric. Food Chem. 54, 8775-8781.

Mandal, V., Mohan, Y., Hemalatha, S., 2007. Microwave assisted extraction - an innovative and promising extraction tool for medicinal plant research. Pharmacogn. Rev. 1, 7-18.

Max, B., Salgado, J.M., Cortés, S., Domínguez, J.M., 2010. Extraction of phenolic acids by alkaline hydrolysis from the solid residue obtained after prehydrolysis of trimming vine shoots. J. Agric. Food Chem. 58, 1909-1917.

Meneses, N.G.T., Martins, S., Teixeira, J.A., Mussatto, S.I., 2013. Influence of extraction solvents on the recovery of antioxidant phenolic compounds from brewer's spent grains. Sep. Purif. Technol. 108, 152-158.

Moreira, M.M., Barroso, M.F., Porto, J.V., Ramalhosa, M.J., Švarc-Gajić, J., Estevinho, L., Morais, S., Delerue-Matos, C., 2018. Potential of Portuguese vine shoot wastes as natural resources of bioactive compounds. Sci. Total Environ. 634, 831-842.

Oroian, M., Escriche, I., 2015. Antioxidants: characterization, natural sources, extraction and analysis. Food Res. Int. 74, 10-36.

Piñeiro, Z., Marrufo-Curtido, A., Serrano, M., Palma, M., 2016. Ultrasound-assisted extraction of stilbenes from grape canes. Molecules 21, 784.

Piñeiro, Z., Marrufo-Curtido, A., Vela, C., Palma, M., 2017. Microwave-assisted extraction of stilbenes from woody vine material. Food Bioprod. Process. 103, 18-26.

Pinelo, M., Sineiro, J., Núñez, M.J., 2006. Mass transfer during continuous solid-liquid extraction of antioxidants from grape byproducts. J. Food Eng. 77, 57-63.

Pintać, D., Majkić, T., Torović, L., Orčić, D., Beara, I., Simin, N., Mimica-Dukić, N., Lesjak, M., 2018. Solvent selection for efficient extraction of bioactive compounds from grape pomace. Ind. Crops Prod. 111, 379-390.

Proestos, C., Komaitis, M., 2008. Application of microwave-assisted extraction to the fast extraction of plant phenolic compounds. LWT - Food Sci. Technol. 41, 652-659.

Rajha, H.N., Boussetta, N., Louka, N., Maroun, R.G., Vorobiev, E., 2015. Effect of 
alternative physical pretreatments (pulsed electric field, high voltage electrical discharges and ultrasound) on the dead-end ultrafiltration of vine-shoot extracts. Sep. Purif. Technol. 146, 243-251.

Ranic, M., Nikolic, M., Pavlovic, M., Buntic, A., Siler-Marinkovic, S., DimitrijevicBrankovic, S., 2014. Optimization of microwave-assisted extraction of natural antioxidants from spent espresso coffee grounds by response surface methodology. J. Clean. Prod. 80, 69-79.

Rombaut, N., Tixier, A.-S., Bily, A., Chemat, F., 2014. Green extraction processes of natural products as tools for biorefinery. Biofuels, Bioprod. Biorefining 8, 530-544.

Ruiz-Moreno, M.J., Raposo, R., Cayuela, J.M., Zafrilla, P., Piñeiro, Z., Moreno-Rojas, J.M., Mulero, J., Puertas, B., Giron, F., Guerrero, R.F., Cantos-Villar, E., 2015. Valorization of grape stems. Ind. Crops Prod. 63, 152-157.

Sánchez-Gómez, R., Zalacain, A., Alonso, G.L., Salinas, M.R., 2014. Vine-shoot waste aqueous extracts for re-use in agriculture obtained by different extraction techniques: phenolic, volatile, and mineral compounds. J. Agric. Food Chem. 62, 10861-10872.

Sánchez-Gómez, R., Alonso, G.L., Salinas, M.R., Zalacain, A., 2017a. Reuse of vine-shoots wastes for agricultural purposes. Handbook of Grape Processing by-Products: Sustainable Solutions. Elsevier, pp. 79-104.

Sánchez-Gómez, R., Sánchez-Vioque, R., Santana-Méridas, O., Martín-Bejerano, M., Alonso, G.L.L., Salinas, M.R.R., Zalacain, A., 2017b. A potential use of vine-shoot wastes: the antioxidant, antifeedant and phytotoxic activities of their aqueous extracts. Ind. Crops Prod. 97, 120-127.

Shen, T., Wang, X.-N., Lou, H.-X., 2009. Natural stilbenes: an overview. Nat. Prod. Rep. 26, 916.
Soural, I., Vrchotová, N., Tříska, J., Balík, J., Horník, Š., Cuřínová, P., Sýkora, J., 2015. Various extraction methods for obtaining stilbenes from grape cane of Vitis vinifera L. Molecules 20, 6093-6112.

Spigno, G., De Faveri, D.M., 2009. Microwave-assisted extraction of tea phenols: a phenomenological study. J. Food Eng. 93, 210-217.

Spigno, G., Tramelli, L., De Faveri, D.M., 2007. Effects of extraction time, temperature and solvent on concentration and antioxidant activity of grape marc phenolics. J. Food Eng. 81, 200-208.

Teixeira, A., Baenas, N., Dominguez-Perles, R., Barros, A., Rosa, E., Moreno, D.A., GarciaViguera, C., 2014. Natural bioactive compounds from winery by-products as health promoters: a review. Int. J. Mol. Sci. 15, 15638-15678.

Vergara, C., von Baer, D., Mardones, C., Wilkens, A., Wernekinck, K., Damm, A., Macke, S., Gorena, T., Winterhalter, P., 2012. Stilbene levels in grape cane of different cultivars in southern chile: determination by HPLC-DAD-MS/MS method. J. Agric. Food Chem. 60, 929-933.

Vinatoru, M., Mason, T.J., Calinescu, I., 2017. Ultrasonically assisted extraction (UAE) and microwave assisted extraction (MAE) of functional compounds from plant materials. TrAC Trends Anal. Chem. 97, 159-178.

Yilmaz, M.B., Guray, U., Guray, Y., Biyikoglu, S.F., Tandogan, I., Sasmaz, H., Korkmaz, S., 2006. Metabolic syndrome negatively impacts early patency of saphenous vein grafts. Coron. Artery Dis. 17, 41-44.

Yu-Qing, S., Xin, T., Xiao-Ming, M., Zi-Wei, X., Tian, W., 2017. ScienceDirect in vitro and in vivo antioxidant activities of three major polyphenolic compounds in pomegranate peel: ellagic acid, punicalin, and punicalagin. J. Integr. Agric. 16, 1808-1818. 